\title{
O sistema das nove cores na reintegração cromática de bens culturais
}

\author{
Ana Bailão
}

\begin{abstract}
Resumo: A seleção das cores mais adequadas para realizar uma reintegração cromática não é normalmente uma questão fácil de resolver. Para utilizar uma paleta restrita, muitos conservadores-restauradores optam por usar as três cores primárias, percebendo a curto prazo que cada fabricante tem as suas cores primárias e que com cada conjunto de três cores-pigmento se obtêm uma gama limitada de tons. Normalmente, segundo a obra, são necessários matizes adicionais para obter tons fora desta gama. O objectivo deste estudo é fazer um levantamento dos conceitos da teoria da cor e propor um sistema alternativo, constituído por nove cores, dois amarelos, dois azuis, dois vermelhos, pelo branco, preto e ainda pela terra de sombra queimada. Nos diversos exercícios demonstrativos recorreu-se às aguarelas Artist's Watercolours da marca inglesa Winsor\&Newton.
\end{abstract}

Palavras-chave: reintegração cromática, cor, nove cores; tendências tonais; aguarelas; Winsor\&Newton.

\section{El sistema de nueve colores en la reintegración cromática de los bienes culturales}

Resumen: La selección de los colores más adecuados para realizar una reintegración cromática generalmente no es un asunto fácil de resolver. Para utilizar una paleta restringida, muchos conservadores optan por usar los tres colores primarios, percibiendo a corto plazo que cada fabricante tiene sus propios colores primarios y con cada conjunto de tres colores-pigmento se puede obtener sólo una gama limitada de tonos. Normalmente, según la obra, es necesario emplear también otros colores adicionales para obtener colores fuera de este rango. El objetivo de este estudio es proponer un sistema alternativo, basado en las normas de la teoría del color, constituido por nueve colores, dos amarillos, dos azules, dos rojos, el blanco, negro y la tierra de sombra quemada. Se recurrió a las acuarelas Artist's Watercolours de Winsor\&Newton.

Palabras-clave: reintegración cromática, color, nueve colores, tendencias tonales, acuarelas, Winsor\&Newton.

\section{The system of nine colours for the retouching of cultural heritage}

Abstract: The selection of the most suitable colours for retouching practice is usually not an easy matter to settle. In order to use a restricted palette, many conservators choose to use the three primary colours, realizing in short term that each paint brand has its own primary colours and that, with each set of three colour-pigments, only a limited range of tones is obtained; additional tints are normally required for tones outside this range. The aims of this study is to undertake a survey of colour theory concepts and to propose an alternative system, based on nine colours: two yellows, two blues, two reds, one white, one black and burnt umber, using the Artist's Watercolours from Winsor \& Newton.

Keywords: retouching, colour, nine colours, colour bias, watercolours, Winsor \& Newton.

\section{Introdução}

A cor, quer sob a forma de luz, quer sob a forma de pigmento, está presente em tudo o que observamos, e constitui um elemento essencial em reintegração cromática, pois desempenha funções múltiplas na visualização dos objectos artísticos. A cor confere continuidade às lacunas e desgastes que podem ocorrer numa dada composição pictórica. Quanto maior for a fidelidade da reprodução da cor a reintegrar com a da superficie cromática original, maior será o realismo e a naturalidade dos resultados observados. 
A cor desempenha também um papel importante na verificação da qualidade de algumas fases das intervenções de restauro, como o caso da aplicação de massas de preenchimento. Não são raras as vezes em que os preenchimentos não ficam correctamente nivelados e que por isso comprometem o resultado final da intervenção. Por exemplo, um mesmo tom verde pode parecer mais escuro em áreas côncavas e mais claro em zonas mais relevadas. Esta variação do matiz na lacuna acentua a percepção do declive e realça um trabalho executado com menor qualidade.

Quando se fala de reintegração cromática surge a questão acerca da escolha das "cores" para realizar a tarefa, isto é, devem usar-se os três tons primários, ou um outro conjunto constituido por seis, doze ou mais matizes? O objetivo deste estudo é sugerir um conjunto de cores para se fazer a reintegração, fundamentando a escolha de matizes na teoria da cor.

\section{A cor}

O processo de percepção de cor pelos seres humanos é algo complexo, contudo pode ser sintetizado em duas etapas fundamentais: captação fisiológica da luz e interpretação cerebral. 0 produto final é a sensação ou estímulo de cor (Kuppers 1975: 24). A justificação destas designações passa por, em sentido estrito, a cor ser um produto sensorial da visão e do funcionamento do cérebro humano, que é subjetivo e não um dado concreto e que começa na retina do olho humano.

O que vulgarmente se chama luz é a radiação electromagnética visível. A organização das radiações electromagnéticas depende do seu comprimento de onda' (González-Cuasante et al. 2005: 26; Tornquist 2008: 29, 30). À totalidade dos comprimentos de onda visíveis pelo olho humano atribuiu-se a denominação de espectro visível (Ball 2001: 25, 38; Hecht 2002: 19-20).

Quando as radiações electromagnéticas visíveis atingem um corpo físico ${ }^{2}$, podem ocorrer um ou mais fenómenos físicos que interferem no processo de percepção da cor. No caso de se tratar de um objecto opaco e colorido, estas radiações visíveis podem ser absorvidas e reflectidas parcialmente. Se o objecto for transparente ou translúcido, estas mesmas radiações são transmitidas, isto é, a luz atravessa o material sem sofrer alterações (Hickethier 1969:6). No entanto, quando a radiação atravessa dois meios distintos, uma parte da energia volta para trás (reflexão), enquanto a restante energia se transmite ao outro meio, acompanhada por uma alteração da direcção de propagação (refração) (Hecht 2002).

Na prática quando a luz é absorvida na sua totalidade vemos preto; quando a luz é reflectida na sua totalidade vemos branco; quando a luz é transmitida o objecto observado é incolor. O estímulo ou sensação de cor que se observa resulta das radiações de energia visíveis não absorvidas pelo objecto ou matéria.

É também importante reter que o modo como os raios luminosos incidem nas superfícies dos objectos altera o modo como são vistos. Se a superfície for plana e lisa há maior reflexão de luz de forma regular ou especular, com o mesmo ângulo incidente e sem alteração de cor, o que corresponde a uma superfície brilhante. Pelo contrário, as superfícies mates, que apresentam ligeiras imperfeições, fazem com que a reflexão se produza de forma irregular ou difusa, podendo haver modificação da cor (González-Cuasante et al. 2005: 34; Saunders 2000: 3-9).

A palavra cor é usada frequentemente com dois sentidos distintos: a que resulta da mistura subtractiva ou a que provem da mistura aditiva. Às substâncias coloridas ou aos materiais que dão 
cor, como as tintas usadas no restauro, associa-se o primeiro fenómeno. Quanto à mistura aditiva, por outro lado, é o resultado da percepção visual de luz que determinados materiais produzem e emanam, como é o caso das fontes de luz ou os dispositivos electrónicos (televisores, écra dos computadores, entre outros). No presente texto será utilizado o termo "cor-pigmento" para a primeira situação, assumindo-se a designação "cor-luz" para o segundo caso.

\section{Léxico}

O léxico da cor utilizado na conservação e restauro é por vezes impreciso. Esta ausência de clareza resulta do facto do estudo científico da cor obrigar à multidisciplinaridade, sendo portanto, um assunto da física, da psicologia, da psicofísica, entre outras. Por este motivo, e consoante os textos, podemos encontrar termos distintos para a mesma qualidade ou atributo.

A explicação das três dimensões ou atributos da cor está definida do ponto de vista físico pela Commission Internationale de l'Eclairage (CIE) (CIE 1987; Fairchild 2005: 85-88). Todavia, a mais corrente e utilizada no campo das artes é a de natureza psicofísica (Urland 1999: 4-5):

- Matiz ou Tom (Hue) define aquilo que associamos usualmente ao conceito de cor (vermelho, verde, amarelo, azul). É a cor-pigmento pura, o comprimento de onda dominante (Fig. 1).

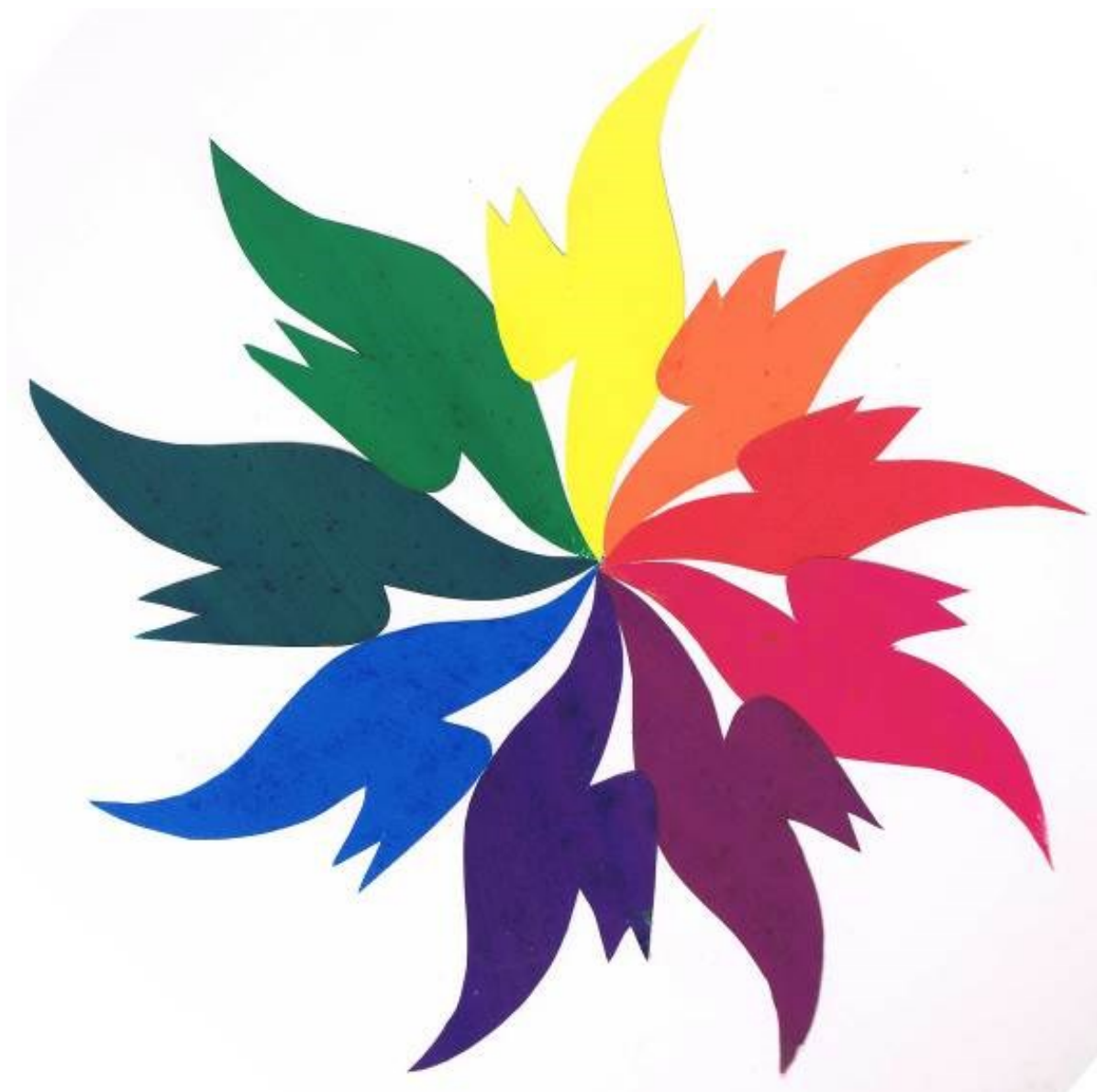

Figura 1: Representação de vários matizes. @Execução técnica e créditos fotográficos de Ana Bailão. 
- Valor ou luminosidade (value) é um atributo que se refere à claridade ou escurecimento que uma cor apresenta quando comparada com a escala de luminosidade do branco e do negro, a escala de cinzentos (Fig. 2 e 3). Esta pode oscilar em níveis sendo a escala acromática de 10 níveis aquela onde se melhor apreciam as diferenças de luminosidade pelo olho humano. A escala é obtida através da adição de branco ou de preto para aclarar ou escurecer uma cor em proporções regulares (Tuan Laka 2013: 58).
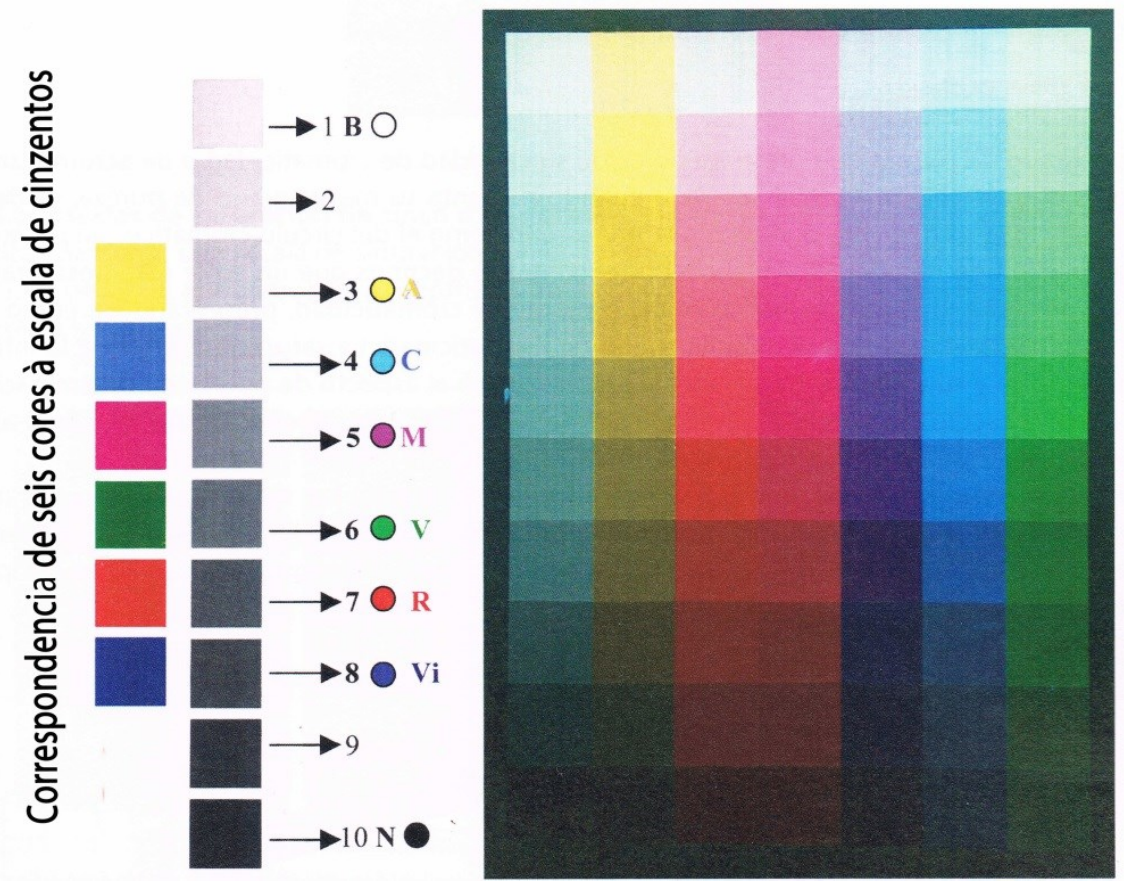

Figura 2: Representação gráfica de seis cores-pigmento segundo a sua luminosidade na escala de cinzas de dez níveis, numerada do branco (1 B) ao negro (10 N): o amarelo é equivalente ao 3 nível, seguido do ciano com 4, o magenta com 5, o verde com 6, o vermelho com 7 e o violeta com 8. llustração de Mercedes Truan Laka (Truan Laka 2013: 57).

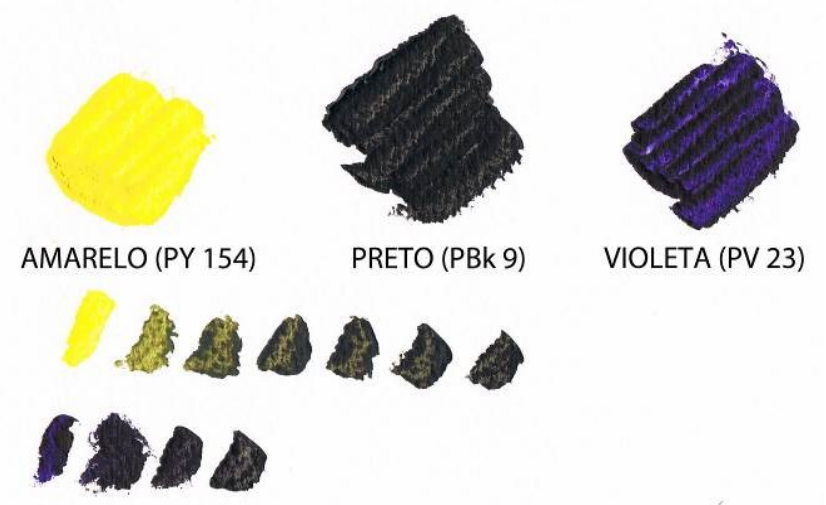

Figura 3: Comparação da luminosidade entre o amarelo (PY 154) e o violeta (PV 23), tendo como referência o preto. O amarelo (PY 154) parece ser mais luminoso porque está mais próximo do branco do que o violeta. Este parece menos luminoso porque está mais próximo do preto. OExecução técnica e créditos fotográficos de Ana Bailão. 
Veja-se o caso da adição das cores-pigmento acromáticas (branco, preto) às três cores primárias (ciano, magenta e amarelo) (Fig. 4). As escalas de cor do amarelo e do vermelho contêm, normalmente, mais gradações facilmente diferenciáveis pelo olho humano do que o azul ou o verde. Isto acontece porque cada escala varia em função do matiz (Loução 1992: 38).

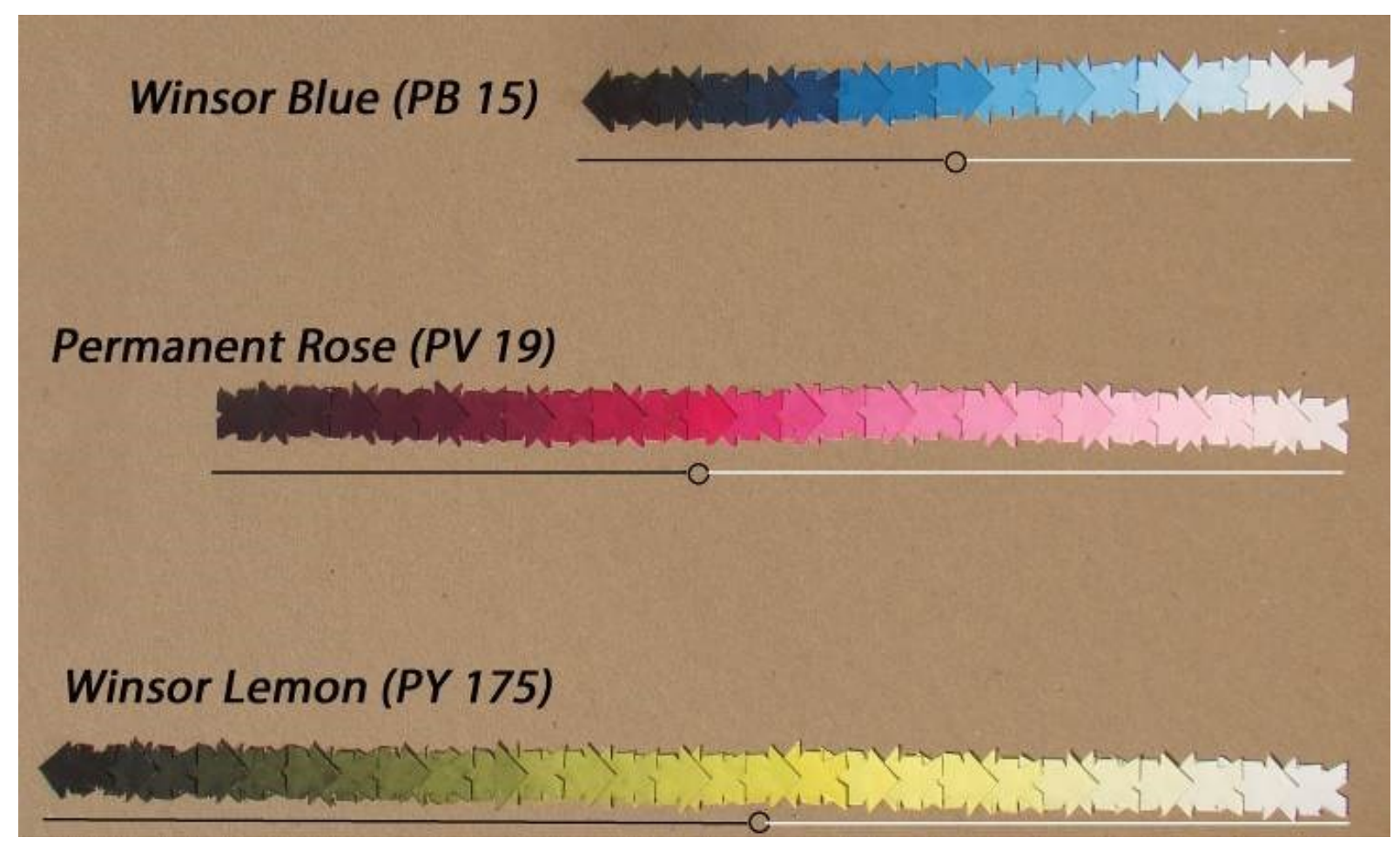

Figura 4: Exemplificação dos resultados obtidos com a adição de Titanium White (PW 6) e de Ivory Black (PBk 9) às três aguarelas primárias da Artist's Watercolours do fabricante Winsor\&Newton (W\&N): Winsor Blue (PB 15), Permanent Rose (PV 19) e Winsor Lemon (PY 175). O pequeno circulo debaixo de cada escala indica a cor retirada diretamente do tubo e a partir da qual se procedeu à gradação através da adição de branco (à direita do circulo) e de preto (à esquerda do círculo). (E) Escalas e créditos fotográficos de Ana Bailão.

- Saturação (Saturation ou chroma) caracteriza o grau de pureza do matiz e descreve a intensidade do tom em relação às cores acromáticas. O nível mais alto de saturação de um matiz é alcançado quando este apresenta uma intensidade de cor similar à do círculo cromático, sem contaminação ou misturas, sobre uma superfície branca (Truan Laka 2013: 58). Um erro comum é pensar que todos os matizes que são aplicados diretamente do tubo são saturados. Todavia, uma terra sombra natural é um amarelo de baixa saturação, um ocre amarelo é um amarelo de média saturação e um amarelo cádmio é um tom de elevada saturação (Fig. 5). O nível mais baixo de saturação caracteriza-se por apresentar um valor cromático baixo, com um matiz próximo do negro, branco ou cinzento. Assim, um matiz perde saturação quando a sua capacidade colorante foi neutralizada. Essa neutralização pode ser realizada de vários modos: pela mistura com branco, com cinzento, com negro ou com a cor complementar (Truan Laka 2013: 58, 59). A cor complementar de um matiz é aquela que mais absorve o seu espectro, como o caso das misturas de vermelho e verde, azul e laranja, amarelo e violeta. 


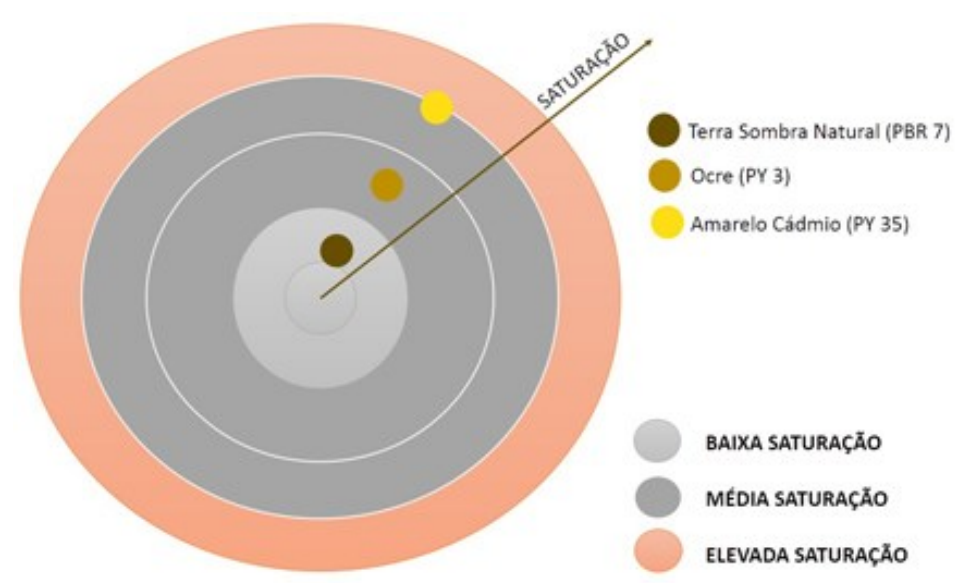

Figura 5: Representação tridimensional dos três níveis de saturação de cor recorrendo a três matizes: terra de sombra natural ( $\mathrm{PBr} 7$ ) de baixa saturação; ocre amarelo de média saturação e amarelo Cádmio (PY 35) de elevada saturação. $\odot$ Esquema de Ana Bailão.

Observando a figura 6 é possível constatar que a luminosidade (Value) e a saturação (Chroma) se relacionam entre si para um determinado matiz (Hue). Esta relação pode gerar alguma confusão, uma vez que é normal os conservadores-restauradores interpretarem uma saturação elevada como uma elevada luminosidade. Como se pode verificar na figura 6 , o vermelho $5 R$ (assinalado com um +) tem uma elevada saturação, /14, mas uma média luminosidade situando-se no valor $5 /$, um valor intermédio na escala de cinzas. Para que este matiz seja mais luminoso é necessário adicionar mais quantidade de branco, o que na prática também significa diminuir a saturação.

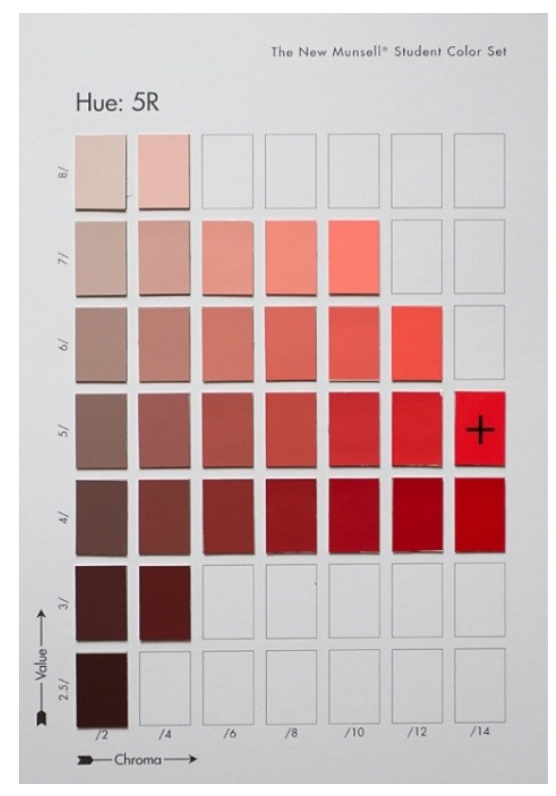

Figura 6: Representação de alguns valores de luminosidade (Value) e de Saturação (Chroma) de um pigmento vermelho na escala de Munsell. $O$ matiz é designado nesta escala por $5 R$ e está assinalado com um símbolo mais (+). A luminosidade é exibida verticalmente (numa escala de 2.5 a 8), enquanto a saturação é indicada horizontalmente (numa escala de 2 a 14). Fotografia de um exercício do conjunto de estudante The New Munsell Student Color Set. @ Créditos fotográficos Ana Bailão. 
O termo Hue, que frequentemente se encontra nos tubos de tinta utilizados em reintegração cromática, é usado para designar todas as tonalidades de cor-pigmento que, permanecendo com determinado matiz, diferem do matiz puro. Por exemplo, Cerulean Blue Hue da Cotman Watercolours da marca Winsor\&Newton (W\&N) significa um tom semelhante ao Cerulean Blue. Nestes casos, os matizes são efectuados a partir de pigmentos alternativos, normalmente menos dispendiosos, mas com semelhanças ao nível dos atributos qualitativos da cor-pigmento (matiz, saturação e luminosidade). Assim, a diferença entre o Cerulean Blue genuíno e o Hue da Cotman está no tipo de pigmento utilizado, bem como na opacidade. O azul cerúleo genuíno é opaco, enquanto a versão Hue é transparente e utiliza o azul de ftalocianina (PB 15). Pelo facto do PB 15 ser transparente, é possível que o produtor tenha adicionado à tinta Cotman uma carga ou um pigmento branco para obter uma opacidade similar ao do Cerulean Blue. O tom Cerulean Blue Hue, apesar de estar próximo do matiz, é parcialmente menos saturado e luminoso que o pigmento puro (Fig. 7). Todavia, são ambos resistentes à luz (Pyle e Pearce 2009: 17; Martel 1855: 9).

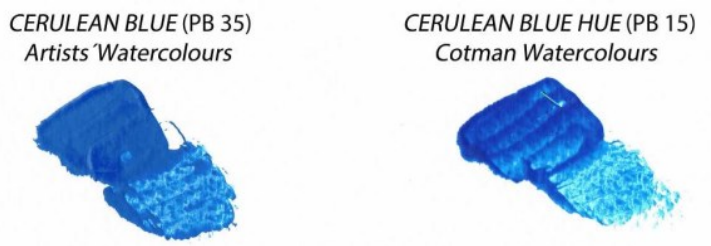

Figura 7: Comparação do pigmento Cerulean Blue da Artists' Watercolours com o Cerulean Blue da Cotman Watercolours, ambos da $W \& N$. Ter em consideração que a fotografia altera os atributos reais dos matizes. OExecução técnica e créditos fotográficos de Ana Bailão.

Importa ainda mencionar que enquanto as cores-pigmento cromáticas são definidas pelo matiz, saturação e luminosidade, isto é, pelos três atributos da cor, as acromáticas (preto, branco e cinza) possuem saturação uniforme em todos os comprimentos de onda e, por isso, são diferenciadas apenas pelo brilho e matiz.

$\mathrm{Na}$ terminologia inglesa existem outros conceitos igualmente importantes na caracterização de uma cor-pigmento. Porém, a maioria, não parecem ter tradução directa para português. Por este motivo, no presente texto, os termos serão indicados em inglês, seguindo-se, a sua definição:

- Masstone - termo que se pode traduzir por tom massa, tom geral ou cor geral. É a observação do pigmento concentrado sobre uma superfície, tal como sai do tubo (Fig. 8).

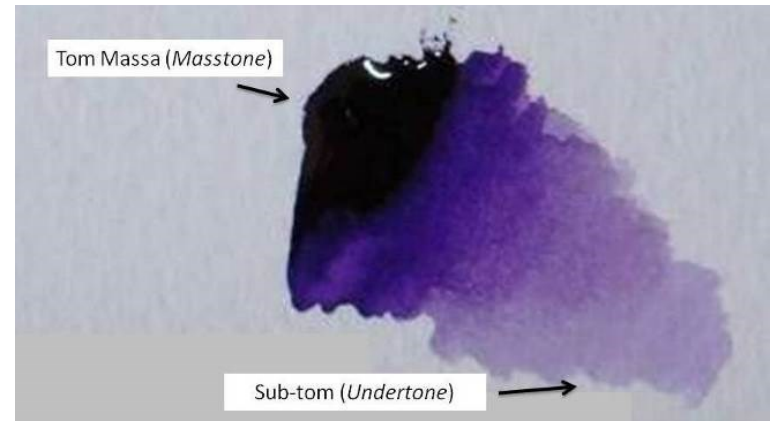

Figura 8: Indicação do tom massa (masstone) e do sub-tom (undertone) com o Permament Mauve (PV 16), Artist's Watercolours, W\&N. OExecução técnica e créditos fotográficos de Ana Bailão. 
- Undertone - termo que poderá traduzir-se por tom diluído ou sub-tom (Fig. 8). É o matiz de um pigmento em fina espessura, que pela sua transparência faz transparecer a cor do suporte. Alguns pigmentos, sobretudo os transparentes, possuem sub-tons distintos dos tons massa, como o Permanent Mauve (PV 16), o verde Viridian (PG 18). Os pigmentos opacos, como o amarelo cádmio (PY 35), apresentam pouca ou nenhuma diferença (Fig. 9).

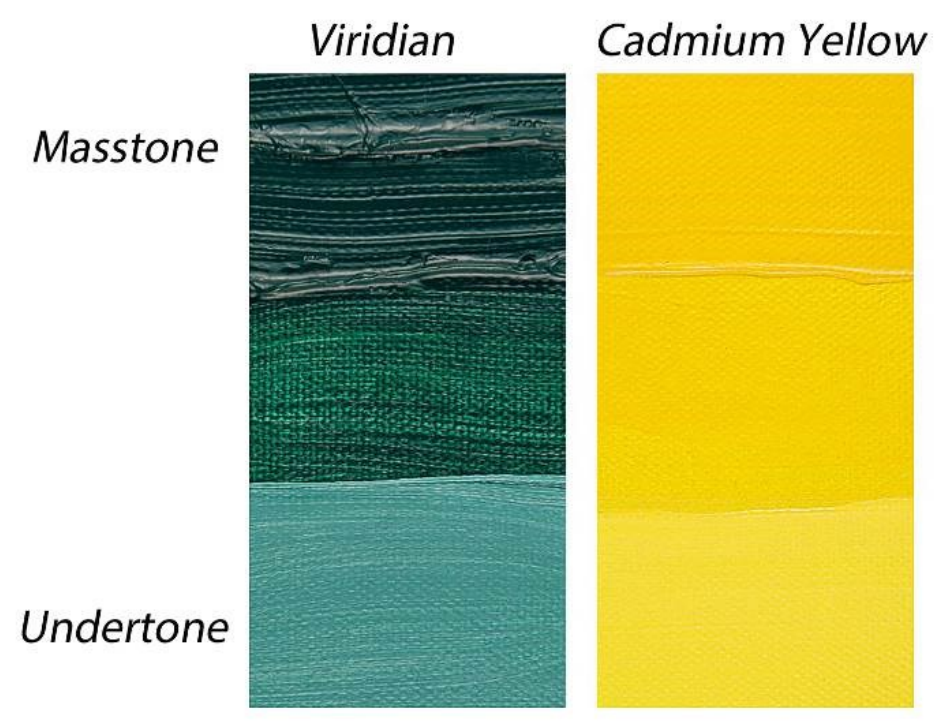

Figura 9: Masstone e undertone do pigmento verde viridian e do cadmium yellow. Como se pode observar a diferença entre a masstone e a undertone é mais evidenciada no pigmento transparente, o viridian.

(c) Execução técnica e créditos fotográficos de Ana Bailão.

Quando se pretende realizar uma reintegração mimética de uma lacuna cujo original tem empaste, o tom massa revela-se muito útil, uma vez que permite a reprodução de áreas opacas e escuras sem a adição de preto, por exemplo. São várias as vezes em que se pode recorrer ao tom massa e ao sub-tom de um matiz numa mesma obra (Fig. 10).

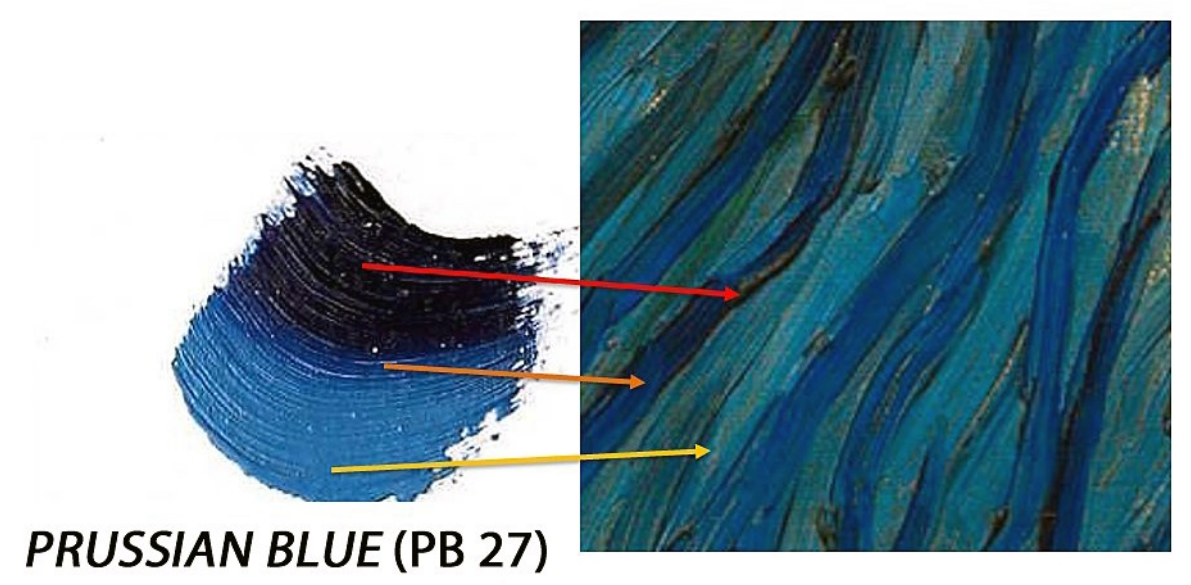

Figura 10: Exemplo da possibilidade de reprodução de vários tons de azul mediante a utilização do masstone, undertone e do tom intermédio do pigmento azul Prussian Blue (PB 27).

○Créditos gráficos de Ana Bailão. 
- Bias (tendência tonal) - Cada cor-pigmento tem uma temperatura de cor: há os tons frios e os tons quentes. Esta característica, também designada de tendência tonal, é facilmente observada quando o matiz é diluído num aglutinante ou misturado com branco. O azul ultramarino (PB 29), por exemplo, é um tom quente quando comparado com outros azuis, como o azul Prússia (PB 27), uma vez que além de azul reflecte vermelho. Por este motivo o PB 29 é designado como um azul com tendência tonal vermelha.

O termo tendência é uma novidade na prática da conservação e restauro, motivo pelo qual pode originar algumas dúvidas, sobretudo relacionadas com o reconhecimento da tendência tonal de um matiz em particular. Para facilitar a identificação o fabricante Winsor\&Newton disponibiliza uma lista de cores quentes e outra de cores frias ${ }^{3}$. As cores quentes podem assumir uma tendência tonal amarela ou vermelha, enquanto as cores frias podem ter uma tendência tonal azul ou verde. Conseguindo fazer esta distinção, a identificação da tendência de cada matiz é mais facilmente perceptível quando é analisada em relação a outro matiz. Por exemplo, o Prussian Blue (PB 27) tem uma tendência tonal esverdeada, quando comparado com o Ultramarine Blue (PB 29) que demonstra ter uma tendência tonal vermelha (Fig. 11). O primeiro é classificado pelo fabricante como um tom frio e o segundo como quente.

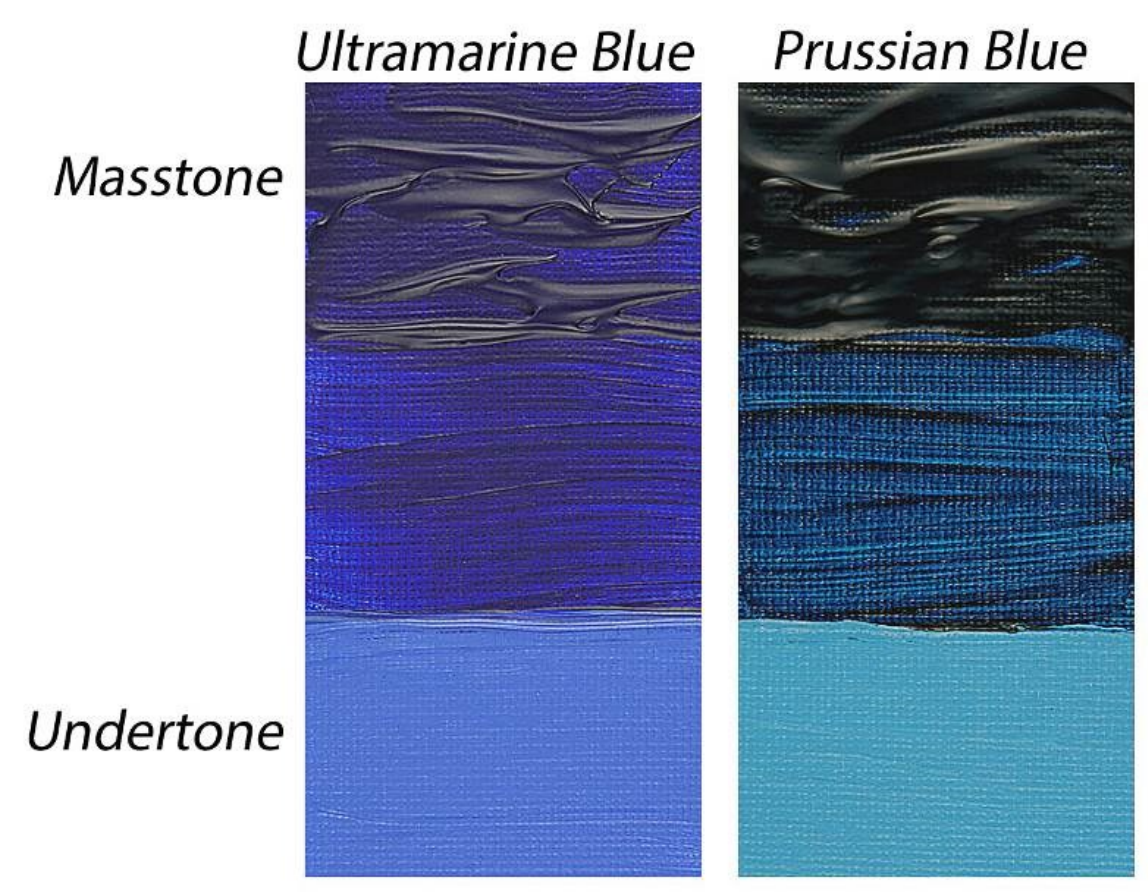

Figura 11: Comparação das tendências tonais entre dois pigmentos: o Ultramarine Blue tem uma tendência tonal mais avermelhada quando comparado com o Prussian Blue, de tendência tonal esverdeada.

○ Execução técnica e créditos fotográficos de Ana Bailão.

Na prática a temperatura de cor de um matiz ajuda a determinar a tendência tonal. Por exemplo, se um vermelho de tendência azul for misturado com azul de tendência verde, como o PB 27, o resultado final será um violeta escuro, um tom menos puro de baixa saturação e luminosidade, pois as tendências tonais são complementares. Para produzir um violeta puro é conveniente misturar um vermelho com tendência azul, como o Permanent rose (PV 19), com um azul de tendência tonal vermelha, como o Ultramarine Blue (PB 29). 


\section{A mistura aditiva, a subtractiva e a óptica}

Além da síntese aditiva e subtractiva, a mistura óptica também desempenha um papel importante na reintegração cromática. A primeira destes sistemas interpreta a cor enquanto resultado da radiação electromagnética (cor-luz), a segunda enquanto consequência da interacção da luz com a matéria e a terceira como uma sensação criada ao nível da retina a partir de dois ou mais elementos coloridos (cor-pigmento).

No processo aditivo são necessárias três fontes de luz para se obter uma ampla diversidade de tons: o vermelho, o verde e o azul. $O$ resultado da mistura das três primárias é branco. A síntese aditiva está presente nos monitores do computador, no telemóvel ou na televisão, entre outros. $\mathrm{Na}$ encriptação de 8 bits dos sistemas computorizados obtêm-se 256 níveis diferentes de intensidade para cada cor-luz primária, que podem ser visualizados e geridos mediante um programa informático de tratamento de imagem, como o caso do conhecido Adobe Photoshop. Através da mescla dos três níveis é possível obter 16.777.216 (256×256×256) tons diferentes. Todavia, no caso dos pigmentos, esta diversidade é menor.

No que diz respeito à síntese subtractiva, tendo como cor base a cor-pigmento elementar acromática branco, consegue-se obter, através da mistura das três cores-pigmento primárias (magenta, amarelo e azul ciano) um matiz próximo do preto (Fig. 12).

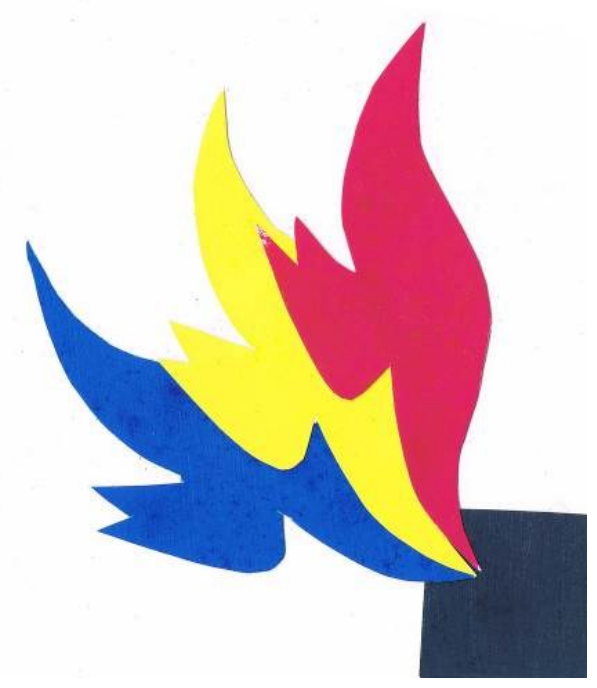

Figura 12: Mistura subtrativa de três cores primárias: Winsor Blue (PB 15), Permanent Rose (PV 19) e Winsor Lemon (PY 175) da W\&N.

A cor-pigmento resultante da síntese é distinta dos matizes iniciais e apresenta uma intensidade luminosa menor que cada um dos tons que formam parte dela (Albers 2007: 40). Assim, por exemplo, a cor-pigmento verde, resultado da subtracção da cor amarelo e ciano, é menos luminosa que os matizes amarelo e ciano no sistema de cor-luz.

No que diz respeito à mistura óptica, esta ocorre quando o nosso sistema visual "origina" uma nova cor através da combinação e fusão de duas ou mais cores-pigmento percecionadas simultaneamente (Tornquist 2008; 54, 55). Trata-se de uma ilusão cromática utilizada frequentemente na reintegração cromática diferenciada, como será explicado mais à frente. 
Para clarificar alguma dúvida acerca da síntese aditiva e óptica, podemos dizer que, enquanto na mistura aditiva há uma combinação de diferentes comprimentos de onda, que se produz antes de chegarem ao olho, na mistura óptica a combinação tem lugar no próprio órgão visual.

\section{As misturas de matizes na reintegração cromática}

Na prática da reintegração cromática os conservadores-restauradores utilizam as tintas de três formas:

a) por mistura das tintas na paleta;

b) por veladuras, sobrepondo camadas transparentes de tinta;

c) intercalando pequenos traços ou pontos/manchas de cor-pigmento que opticamente se misturam, completamente ou parcialmente, consoante a distância de visualização, e que originam as técnicas de reintegração diferenciada.

A mistura na paleta de uma tinta depende da interacção entre aglutinantes e pigmentos. Do mesmo modo que a luz pode ser reflectida da superfície da camada cromática sem interagir com o colorante, contribuindo para uma cor pouco saturada, a luz pode também ser reflectida da superfície das partículas individuais dos pigmentos. A quantidade de luz reflectida depende da diferença entre os índices de refração ${ }^{4}$ do pigmento e do aglutinante envolvente. Este fenómeno de interacção da luz com o meio denomina-se por dispersão e pode ocorrer quando a luz passa através de um meio que não é completamente transparente.

Numa situação em que os grãos dos pigmentos não estão bem aglutinados, como por exemplo no caso dos pastéis secos, a mistura de cores obtida é sobretudo aditiva, e isto acontece porque não se tem um aglutinante a "molhar" ou a envolver todas as partículas do pigmento e a conferir transparência à tinta. Se houver ar nos espaços entre o aglutinante e os grãos, a luz será dispersada, aumentando a luminosidade e reduzindo a saturação de cor (Gottsegen 2006: 154-198; Mayer 2006: 73-43).

O índice de refracção de um pigmento é também importante porque o poder de cobertura dos pigmentos (semi-opacos ou transparentes) é directamente proporcional ao aumento de índice de refracção dos grãos. Quando os pigmentos estão secos, em pó, em contacto com o ar, os grãos reflectem mais luz do que quando estão aglutinados. A diferença entre os índices de refracção dos pigmentos e os dos aglutinantes é também directamente proporcional à reflexão de luz da tinta. Quanto mais elevado é o índice de refracção dos pigmentos e mais baixo é o do aglutinante, maior é a reflexão de luz e, no caso dos pigmentos brancos, maior é o do poder de cobertura e da brancura. Quando o índice de refracção é similar entre pigmentos e aglutinante, os primeiros parecem mais translúcidos, por haver menos reflexão de luz. São, por isso, mais eficazes quando usados para velaturas; mas se os pigmentos tiverem índices de refracção mais elevados do que os aglutinantes, parecerão mais opacos (Gettens e Stout 1966: 147, 148a, 148b, 148c, 148d). É o caso dos pigmentos cádmios que são opacos em goma-arábica, óleo, acrílico, entre outros.

Quando o conservador-restaurador recorre à aplicação de velaturas, seja para minimizar desgastes ou para concluir a reintegração de determinada lacuna, constata que a luz atravessa ambas as camadas, o que resulta na mistura subtractiva, pois há absorção de luz na matéria. Todavia, se a camada superior não for perfeitamente transparente, é possível que alguma da luz que incide sobre ela seja difusa. Isto na prática significa, por exemplo, que o efeito obtido com a sobreposição 
de uma laca vermelha sobre um azul opaco é completamente diferente da sobreposição de um azul opaco sobre uma laca vermelha. O motivo deste efeito está relacionado com o índice de refracção das lacas e corantes que é comparativamente mais baixo que os dos pigmentos (Gettens e Stout 1966: 144, 145).

Nos momentos em que duas ou mais cores são percepcionadas simultaneamente, o nosso sistema visual, através da fusão desses tons, origina uma nova cor. Como mencionado, trata-se de uma ilusão cromática designada por "síntese ou mistura óptica" (Tornquist 2008: 54, 55). Na prática, este efeito ocorre quando o observador contempla, a uma certa distância, a reintegração cromática diferenciada, efectuada com traços ou pontos, dando-se aqui como exemplo as técnicas conhecidas como selezione cromatica e o pontilhismo (Fig. 13).
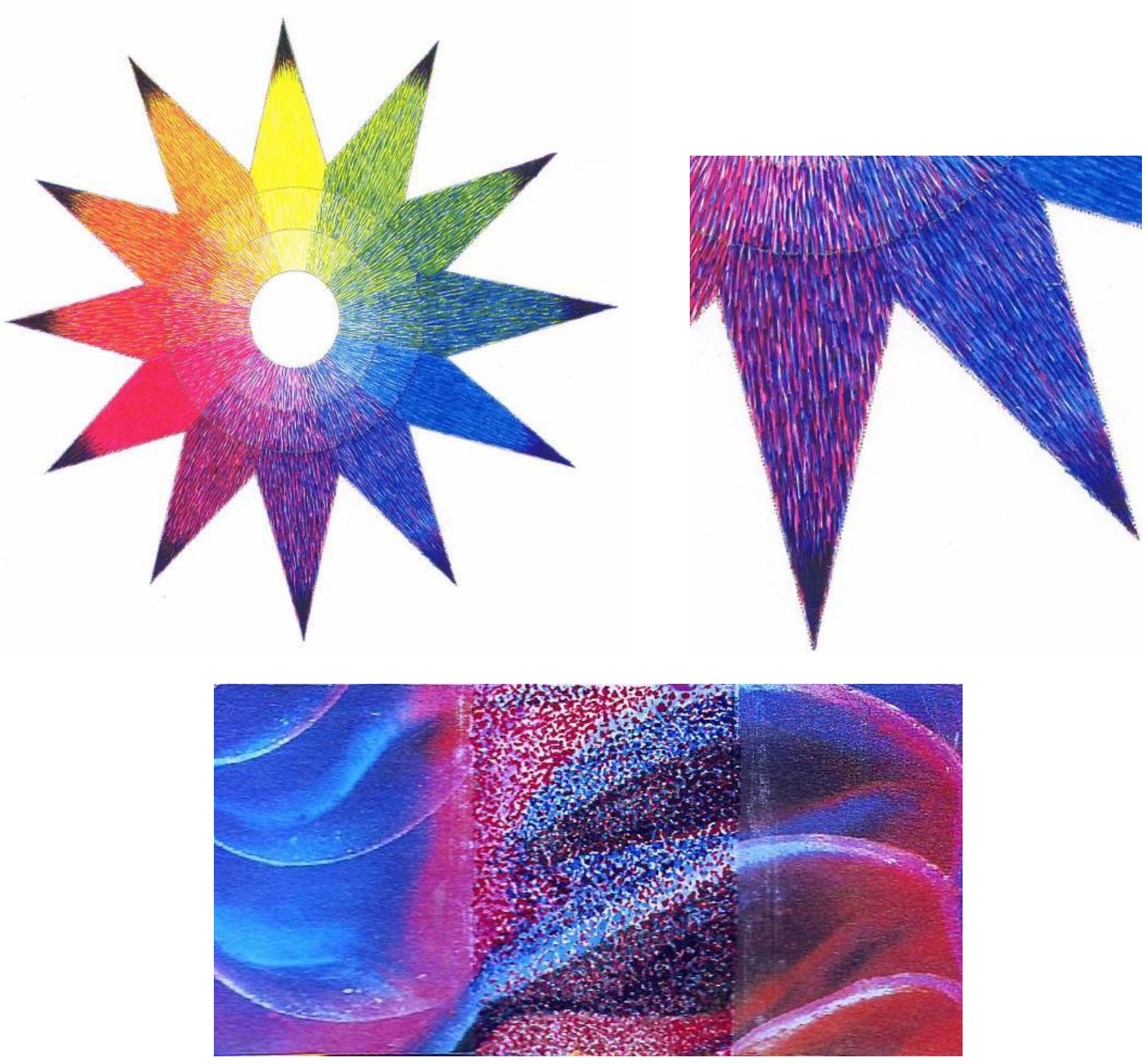

Figura 13: Exemplos de duas técnicas realizadas em dois workshops de reintegração cromática: selezione cromática (em cima) por Mariana Sottomayor na Universidade Católica Portuguesa (UCP) e o pontilhismo (em baixo) por Helena Alexandra no Instituto de Artes e Oficios (IAO) da Fundação Ricardo do Espírito Santo Silva (FRESS). @Créditos fotográficos de Ana Bailão. 
Este fenómeno óptico deve-se ao facto das células receptoras da retina não conseguirem resolver individualmente cada um dos pontos/traços, uma vez que são, na maior parte das vezes, de pequenas dimensões. Quanto menor o tamanho e maior a distância, mais se intensifica o fenómeno. Em vez de misturar na paleta o amarelo e o azul, aplicam-se ambas as cores-pigmento sob a forma de pontos. Esta técnica foi empregue por George Seurat e embora se pense que se conseguiam obter tons mais saturados e luminosos, o resultado final de uma mistura óptica de matizes de elevada saturação são tons pouco saturados (Briggs 2012).

\section{As cores primárias e a mistura de tintas}

No processo subtractivo é vigente a teoria de que existem três cores fundamentais, a partir das quais se pode obter uma ampla gama de tons: o amarelo, o vermelho e o azul. Embora estes três matizes, quando misturados, possam gerar vários tons, não conseguem produzir todas as corespigmento como o violeta ou o verde puro. Como afirma Betty Edwards (Edwards 2006: 21, 22), "(...) as cores utilizadas pelos pintores não são necessariamente verdadeiras cores espectrais". Segunda a autora "(...) os pintores devem complementar os três primários com outros pigmentos cujas estruturas químicas sejam puras na mistura". Para que isso aconteça é necessário utilizar outros dois matizes cujas tendências tonais não sejam complementares. Veja-se o seguinte exemplo: se um vermelho de tendência amarela for misturado com um azul de tendência tonal verde não se consegue obter um tom violeta puro. Para o efeito tem de se recorrer a um matiz menos próximo da cor magenta, com uma tendência tonal para o azul e um azul com uma tendência tonal avermelhada (Fig. 14).

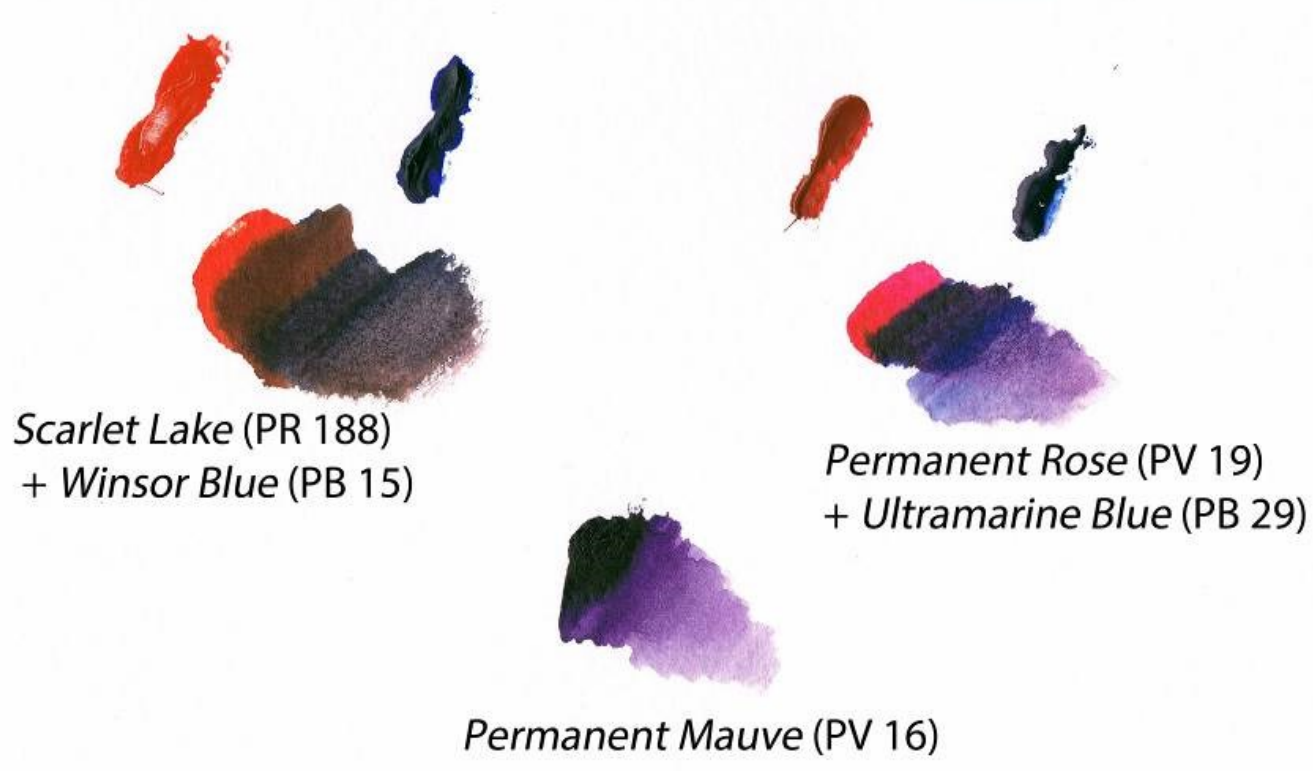

Figura 14: Mistura de tendências tonais: a mistura da esquerda foi realizada com Scarlet Lake (PR 188) (tendência tonal amarela) + Winsor Blue (PB 15) (de tendência tonal verde) e resultou num tom um pouco castanho; a obtenção de um violeta puro, similar ao Permanent Mauve (PV 16), só foi possível com a utilização de um vermelho de tendência tonal azul, como o Permanent Rose (PV 19), e um azul de tendência tonal vermelha, como o Ultramarine Blue (PV 19), como se pode observar na mistura da direita. (Execução técnica e créditos fotográficos de Ana Bailão. 
Quando se pretende reproduzir um tom intenso, saturado e luminoso, através de uma mistura de dois matizes, é fundamental ter em conta a tendência tonal. O conservador-restaurador irá obter tons mais puros com uma paleta constituída por um ciano, um amarelo e um magenta, e tons menos puros, de baixa saturação e luminosidade, também designados coloquialmente por "tons quebrados", com um azul, amarelo e vermelho.

Posto isto, é importante anotar que existe uma diferença significativa entre a teoria e a prática da cor, pois os matizes disponibilizados no mercado como cores primárias variam em função do fabricante e do aglutinante utilizado. Embora o ciano, o amarelo e o magenta sejam de facto as três cores primárias, os tons disponíveis afastam-se em vários aspectos importantes das características definidas e consideradas como ideais na teoria da cor para a mistura subtractiva:

a) Cada conjunto de três cores-pigmento pode obter apenas uma gama limitada de tons; matizes adicionais são normalmente necessários para obter tons fora desta gama. Ao contrário do que acontece com o sistema CMYK (cyan, magenta, yellow e black) utilizado pelas impressoras, onde ciano, amarelo e magenta podem gerar hipoteticamente todas as cores RGB, os pigmentos considerados ideais de ciano, amarelo e magenta simplesmente não existem (Briggs 2012).

b) Os pigmentos actualmente disponibilizados no mercado como cores primárias não se aproximam do tom do ciano e do magenta. Os pigmentos amarelos estão disponíveis numa gama de cores diversa, mas o mesmo não acontece com as outras duas primárias. Por exemplo, o tom aproximado do magenta ideal é o Quinacridona Magenta (PV 19), porém este tom, é nitidamente mais vermelho do que o magenta ideal da teoria da cor. Da mesma forma, o tom próximo do ciano ideal é o pigmento azul de ftalocianina green shade (PB 15:3), que é muito mais azul do que o ciano ideal (Briggs 2012, Edwards 2006: 22, 23).

\section{O sistema das seis cores: dois amarelos, dois vermelhos e dois azuis}

Pelo facto das três cores primárias - ciano, amarelo e magenta - reproduzirem uma limitada gama de matizes, há um sistema alternativo, o sistema das seis cores, que se baseia nas três cores primárias, todavia com diferentes tendências tonais (duas para cada primária) com o objetivo de obter uma gama cromática mais alargada. Esta paleta de seis tons varia em função do produtor de tintas mas pode ser uma opção para quem quer fazer reintegração cromática com uma paleta restrita. O sugerido é sempre um vermelho com uma tendência tonal amarela (yellow shade), um vermelho blue shade, um azul green shade, um azul red shade, um amarelo red shade e um amarelo green shade. Por exemplo, pelo facto de se ter dois vermelhos é mais fácil garantir violetas e laranjas mais puros.

Além de multiplicar o número de tons, a diferença entre este sistema e o das três primárias está também nas variáveis em jogo, tais como a opacidade, o poder de tingimento, a granulometria, consoante o tipo de tom utilizado. As seis cores recomendadas pela Winsor \& Newton Artists' Watercolour (Winsor \& Newton 2005: 6) são: Winsor Lemon (PY 175), Winsor Yellow (PY 154), French Ultramarine (PB 29), Winsor Blue (Green Shade) (PB 15), Permanent Rose (PV 19) e Scarlet Lake (PR 188) (Fig. 15). 


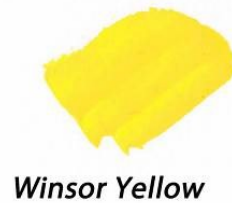
(PY 154)

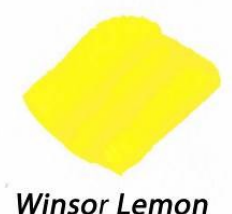

(PY 175)

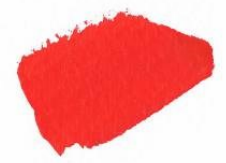

Scarlet Lake (PR 188)

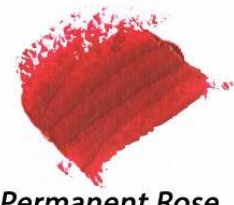

Permanent Rose (PV 19)

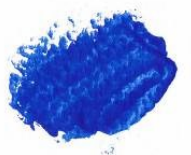

French Ultramarine

(PB 29)

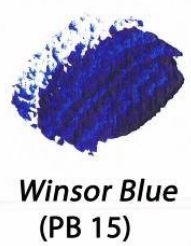

Figura 15: Os seis matizes recomendados pela W\&N Artists' Watercolour. OPreparação de tintas e créditos fotográficos de Ana Bailão.

Como referido, cada fabricante tem os seus matizes, e estes podem variar em função do tipo de tinta/aglutinante (aguarela, guache, acrílicos, óleos, entre outros) e também se forem de qualidade de artista (por exemplo, Artists' Watercolour) ou de estudante (por exemplo, Cotman Watercolour). Se a W\&N recomenda as seis aguarelas de qualidade de artista supracitadas, a Schmincke Horadam ${ }^{\circledR}$ Aquarell sugere Lemon Yellow (PY 3), Cadmium Yellow light (PY 35), Cadmium Red Light (PR 108), Permanent Carmine (PR 83:1), Ultramarine Finest (PB 29) e Prussian blue (PB 27) (Schmincke 2010: 14). O único pigmento em comum é o azul ultramarino (PB 29).

Partindo dos matizes aconselhados é fundamental ter em consideração as propriedades de cada um deles, sendo estas indicadas na tabela seguinte (Tab.1):

Tabela 1: Propriedades dos seis matizes recomendados pela Artists' Watercolour da W\&N (Winsor \& Newton 2005: 12).

\begin{tabular}{|c|c|c|c|c|c|c|}
\hline Nome comum & Série & $\begin{array}{c}\text { C.I. } \\
\text { Name }\end{array}$ & Descrição química & ASTM & $\begin{array}{l}\text { Transparência. } \\
\text { /Opacidade }\end{array}$ & $\begin{array}{l}\text { Poder } \\
\text { tingimento }\end{array}$ \\
\hline Winsor Yellow & 1 & PY 154 & Benzimidazolona & I & Semi-transparente & Baixo \\
\hline Winsor Lemon & 1 & PY 175 & Benzimidazolona & II & Semi-transparente & Baixo \\
\hline $\begin{array}{l}\text { French } \\
\text { Ultramarine }\end{array}$ & 2 & PB 29 & $\begin{array}{l}\text { Aluminossilicato de } \\
\text { sódio e cálcio com } \\
\text { enxofre }\end{array}$ & I & Transparente & Baixo \\
\hline $\begin{array}{l}\text { Winsor Blue } \\
\text { (Green Shade) }\end{array}$ & 1 & PB 15 & Ftalocianina de cobre & II & Transparente & Elevado \\
\hline Permanent Rose & 3 & PV 19 & Quinacridona & I & Transparente & Elevado \\
\hline Scarlet Lake & 2 & PR 188 & Arilamida BON & II & Semi-transparente & Moderado \\
\hline
\end{tabular}


Na primeira coluna tem-se a indicação da Série. Esta está directamente associada ao preço relativo da tinta e é determinada, principalmente, pelo custo do pigmento. A Série 1 é mais económica que a Série 4.

Cada pigmento pode ser universalmente identificado pelo Nome de Índice de Cor [Colour Index Nome (C.I.Name)]. Assim, como se pode observar na segunda coluna, o Winsor Lemon é designando por Pigment Yellow 154, que abreviado fica PY 154.

Na terceira coluna está a descrição química dos pigmentos presentes na tinta e na quarta coluna a estabilidade da cor à luz segundo a norma definida pela American Society for Testing and Materials (ASTM). Na coluna seguinte é anotada a transparência ou opacidade das tintas e na última coluna é indicado o poder de tingimento $(\mathrm{T})$ das cores-pigmento.

Como é possível constatar, três dos matizes são transparentes e três são semi-transparentes. Este dado é muito importante pois impossibilita a reprodução de tons opacos. No caso de ser essencial produzirem-se tons opacos pode-se optar pela versão deste sistema de seis matizes em guache. Os guaches recomendados pela W\&N são: Lemon Yellow (PY 3); Permanent Yellow Deep (PY 65); Phthalo Blue (PG 7 + PB 15); Ultramarine (PB 29); Flame Red (PR 170+PO 72) e Alizarin Crimson (PR 83). Todavia, ao contrário do que acontece com as aguarelas, nestes guaches há mais mistura de pigmentos no mesmo tubo, o que tem, normalmente, implicações na estabilidade das tintas. Existem marcas alternativas, de elevada qualidade, que optam por ter em maioria aguarelas/guaches constituídas por um só pigmento, como são os casos das marcas M.Graham e Schmincke.

Continuando com as aguarelas, a informação referente à estabilidade à luz indica que se tem três tons com uma excelente estabilidade (Winsor Yellow, French Ultramarine, e Permanent Rose) e três com uma estabilidade muito boa (Winsor Lemon, Winsor Blue (Green Shade) e Scarlet Lake).

Esta paleta de seis cores tem dois matizes com elevado poder de tingimento, Winsor Blue $e$ Permanent Rose. Por outras palavras o Winsor Blue (Green Shade) terá um efeito dominante em qualquer mistura, enquanto o French Ultramarine não terá um efeito significativo. Para controlar o poder colorante destas cores-pigmento é necessário adicionar apenas pequenas quantidades de tinta à mistura, repetidas vezes, até que o matiz desejado seja alcançado.

Para misturar os matizes na paleta é importante definir algumas regras:

a) quando se mistura mais de três tons, a mescla deverá ser faseada, isto é, fazer uma mistura A com dois tons e depois outra mistura $B$ com mais dois tons. O matiz pretendido deverá ser a resultado da Mistura $A$ + Mistura $B$ e não a mistura simultânea das quatro corespigmento para evitar uma perda substancial de saturação (Fig. 16). A mistura de diferentes pigmentos resulta numa neutralização cromática entre eles (de la Roja de la Roja 2001; 97) por ocorrer mais absorção de luz. A mistura bipartida permite ajustar os matizes individualmente com maior perceção dos atributos da cor de cada tom, aferindo as proporções sem interferir com a pureza das cores-pigmento.

b) a representação tridimensional dos matizes num circulo cromático facilita a identificação da saturação, das tendências tonais e das cores-pigmento complementares. 

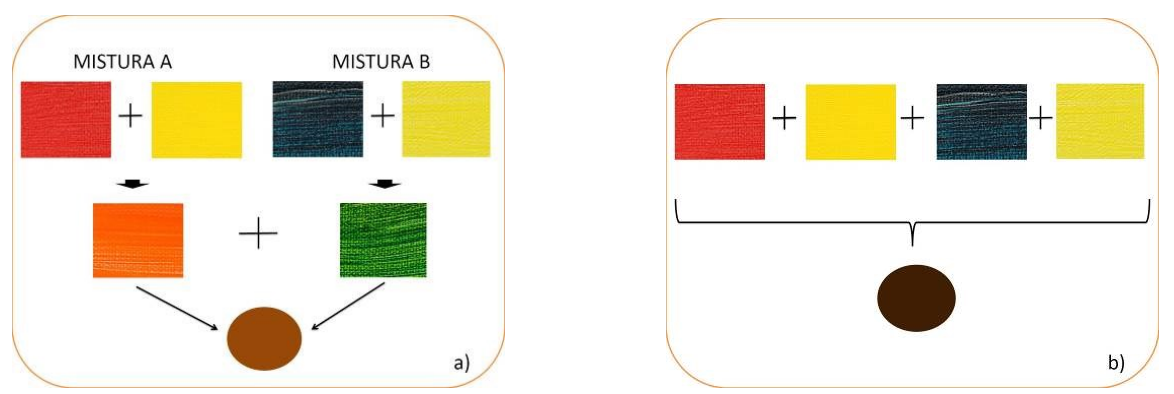

Figura 16: Mistura de tintas: a) Modo mais correcto para efectuar a mistura de quatro matizes; b) modo menos correcto, uma vez que leva a perda de saturação. @Esquema gráfico de Ana Bailão.

Actualmente existem disponíveis na internet diversos círculos cromáticos com a representação colorimétrica de aguarelas, guaches, tintas acrílicas, entre outros. A maioria é produzida por artistas plásticos, como o de Bruce MacEvoy, o de Stephen Quiller e o de Jim Kosvanec, ou pelos fabricantes como o caso da Schmincke. Esta marca de tintas disponibiliza no catálogo das aguarelas Horadam Aquarell a disposição colorimétrica das suas cores (Schmincke 2010: 11). No próximo exercício será utilizado o círculo cromático de Bruce MacEvoy, elaborado em 2009 (Fig. 17). Pretende-se demonstrar a importância do conceito das tendências tonais de cor na mistura das seis cores selecionadas.

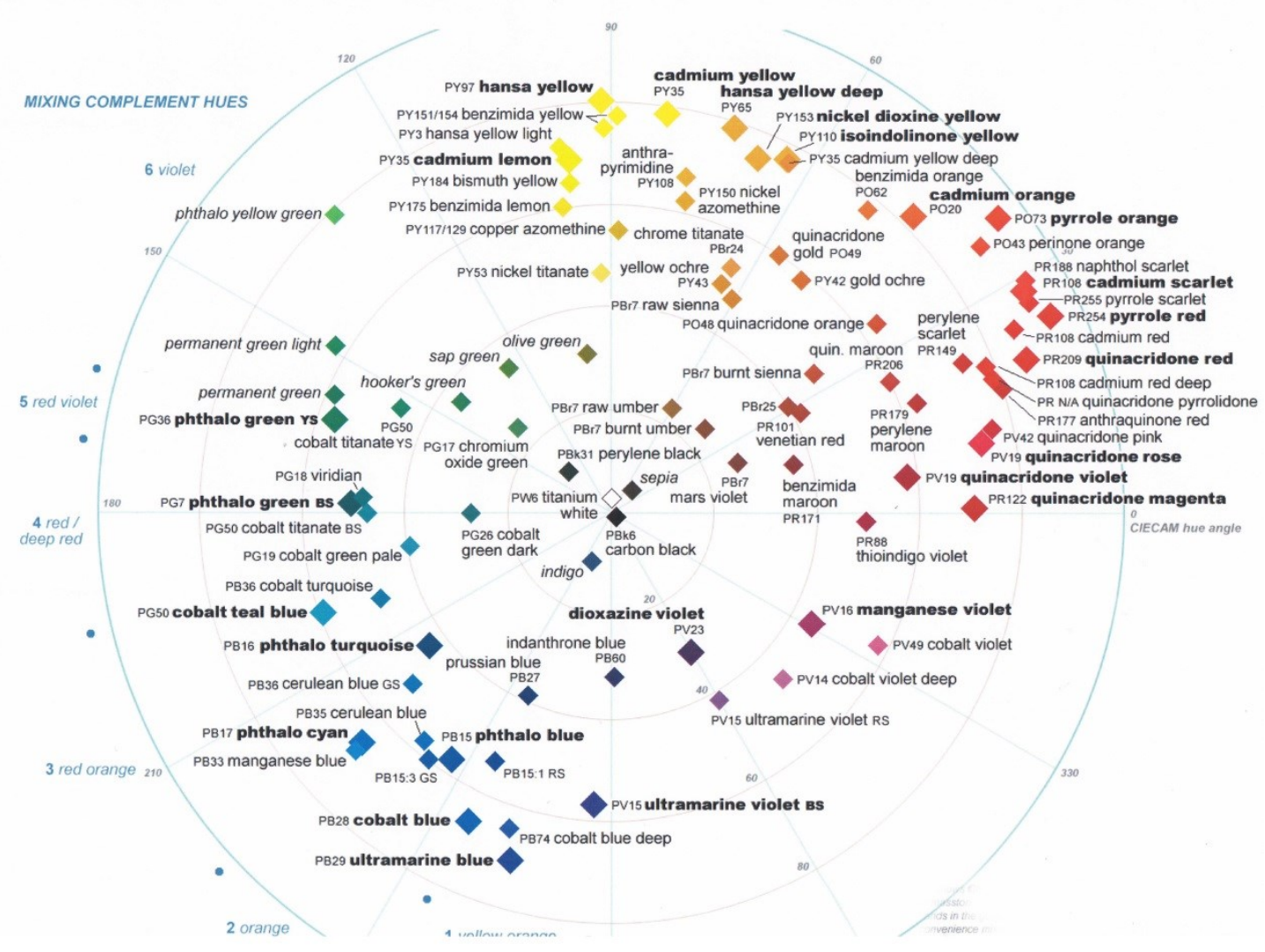

Figura 17: Circulo cromático de Bruce MacEvoy com a representação de aguarelas de várias marcas comerciais, entre as quais a Winsor\&Newton, no modelo CIE 2002 Interim Color Appearance Model (CIECAM02), com observador padrão $10^{\circ}$ e iluminante E. Disponível em http://www.handprint.com/HP/WCL/cwheel06.html. 
Os círculos cromáticos auxiliam no raciocínio acerca da localização dos matizes, da saturação, da tendência tonal e da mistura de tons complementares. Por exemplo, neste caso, os matizes mais saturados localizam-se no exterior do círculo, enquanto os tons mais suaves e neutros (como o branco, preto e cinzento) estão no centro do círculo. À medida que um determinado tom se aproxima do centro, os matizes ficam menos saturados. Todavia, é importante ter em conta que apesar de serem ferramentas de apoio extremamente úteis, tem evidentes margens de erro, uma vez que os pigmentos variam de matiz em função do fabricante e do aglutinante adicionado, e porque não são precisos na determinação do resultado de uma mistura X ou Y. A especificidade das medições também é relevante. Este círculo cromático de Bruce MacEvory será mais útil para uma paleta de aguarelas do que para uma paleta de acrílicos, pelo facto de ter sido executado através da medição colorimétrica de aguarelas.

Para que se perceba a utilidade de um círculo cromático desta tipologia será apresentado de seguida um estudo de caso. Pretende-se reproduzir experimentalmente o tom da terra de sombra queimada da Artist's Watercolour da Winsor\&Newton (W\&N), de tendência amarela, através do uso do sistema das seis cores acima citado.

Para obtenção de um matiz terra de sombra queimada de tendência amarela e de baixa saturação, similar à aguarela da $W \& N$, é necessário que as tintas misturadas sejam complementares (vermelho e verde), mas que tenham tendências tonais similares. Uma vez que o objectivo é produzir a cor tradicional castanha, será utilizado um vermelho com tendência amarela e um verde com tendência amarela para que se mantenha a tendência e não se perca luminosidade.

Na figura 18 estão representadas as tendências tonais das seis cores para comparação. Como podemos constatar, o Permanent Rose (PV 19) tem uma tendência azul quando comparado com o Scarlet Lake (PR 188) que tem uma tendência amarela. Assim, para reproduzir uma sombra queimada com tendência amarela, na eleição do vermelho mais adequado deverá recorrer-se ao Scarlet Lake (PR 188). Na figura 19 estão indicados os matizes obtidos através da mistura das seis cores.
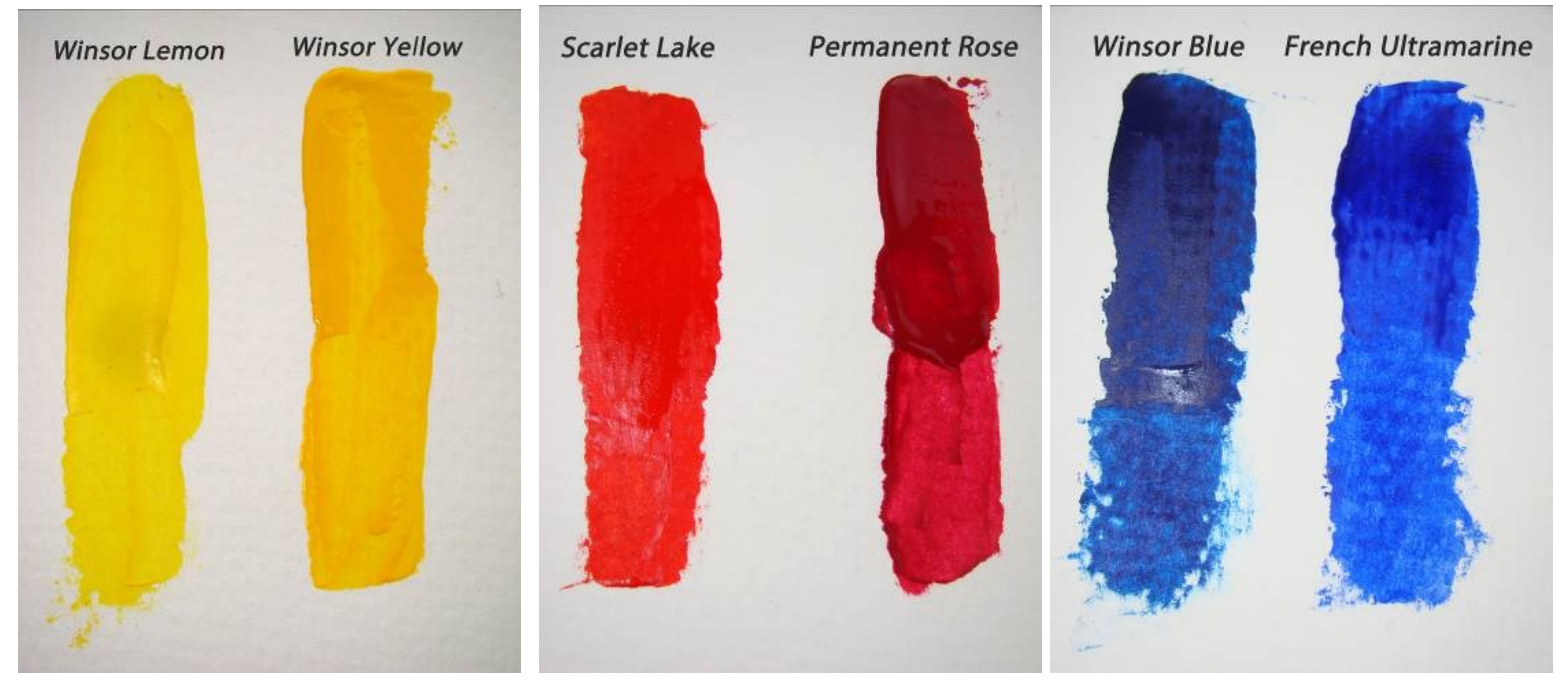

Figura 18: Representação dos seis matizes lado a lado para comparação das tendências tonais. CExecução técnica de Ana Bailão. 


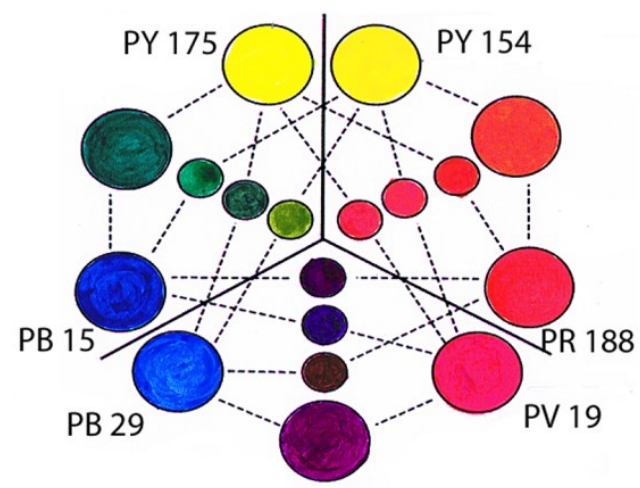

Figura 19: Representação dos matizes obtidos através da mistura de tendências tonais. É importante ter em consideração a alteração de cor proporcionada pela digitalização. O esquema foi adaptado do sítio Foutain Studio Learning to Mix Colors, disponível em http://fountainstudio.com/watercolor\%20tips/tip-mixing_colors.html.

É ainda importante considerar que o Scarlet Lake (PR 188) possa ser demasiado vermelho para o objectivo. Talvez seja necessário adicionar um amarelo para intensificar a tendência amarela de PR 188 e ganhar luminosidade. O amarelo mais adequado é o PY 154, uma vez que o PY 175 tem uma tendência complementar ao vermelho, isto é, verde, favorecendo a obtenção de tons pouco saturados e luminosos. No que diz respeito à escolha do verde, convém ter também uma tendência amarela. As aguarelas mais adequadas são o azul PB 15 e o amarelo PY 175.

Na figura 20 pode-se observar a localização espacial das sete cores: os dois amarelos, os dois vermelhos, os dois azuis e a sombra queimada. Importa referir que a localização geométrica das cores encontra-se redistribuída por 12 secções, através das quais se pode caracterizar o matiz e as tendências tonais. O nível de saturação é determinado em função da distância entre o centro e a periferia do círculo.

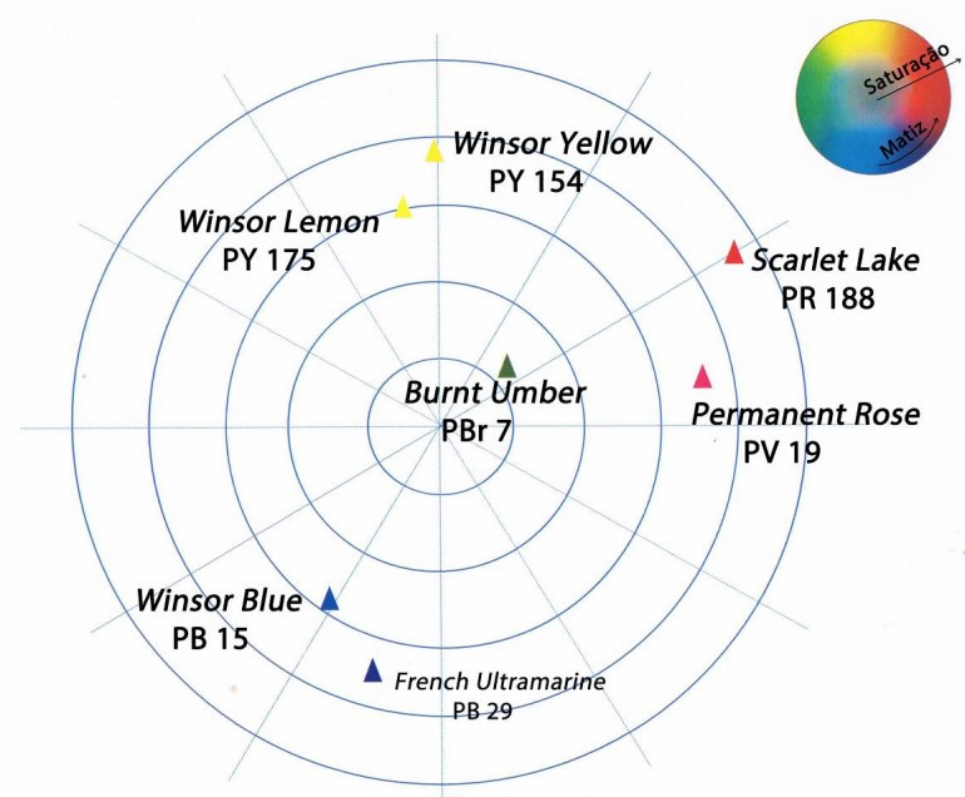

Figura 20: Localização geométrica das sete cores no círculo cromático. A leitura do matiz e das tendências tonais é feito em torno do círculo, enquanto a identificação dos níveis de saturação é feita do centro para a periferia do círculo. @Esquema adaptado por Ana Bailão. 
Fazendo uma análise dos matizes e das tendências tonais do círculo cromático da figura 20, constata-se que entre os vermelhos e os amarelos geometricamente mais próximos de Burnt Umber (PBr 7) são o Scarlet Lake (PR 188) e o Winsor Yellow (PY 154). O PR 188 é uma aguarela bastante vermelha e com tendência amarela, uma vez que está localizada no limite da secção dos vermelhos do círculo cromático. O mesmo acontece com o PY 154 que é um amarelo com uma tendência vermelha. $O$ resultado desta mescla, à qual se atribui o nome de Mistura $A$, resultará num vermelho alaranjado.

Em relação ao verde complementar necessário para reproduzir Burnt Umber é aconselhável que seja obtido através da mistura de um azul e de um amarelo de tendências amarelas (não vermelhas). O produto final da Mistura A [vermelho alaranjado] com um verde avermelhado seria um castanho muito avermelhado, distanciando-se do matiz que se pretende reproduzir. O French Ultramarine (PB 29) é assim excluído da mistura. O azul mais adequado será portanto o Winsor Blue (PB 15) de tendência amarela, ao qual será adicionado o Winsor Lemon (PY 175), devido à proximidade geométrica com o azul mencionado.

A mescla das tintas foi realizada com uma espátula por ser prático no doseamento e manipulação das tintas. A mistura das aguarelas na paleta foi executada em três fases para evitar a perda de saturação:

1a Fase: Mistura A: Scarlet Lake (PR 188) + Winsor Yellow (PY 154) (Fig. 21)

2a Fase: Mistura B: Winsor Lemon (PY 175) + Winsor Blue (PB 15) (Fig. 22)

3a Fase: Mistura A + Mistura B $=\mathrm{PBr} 7$ (Fig. 23)

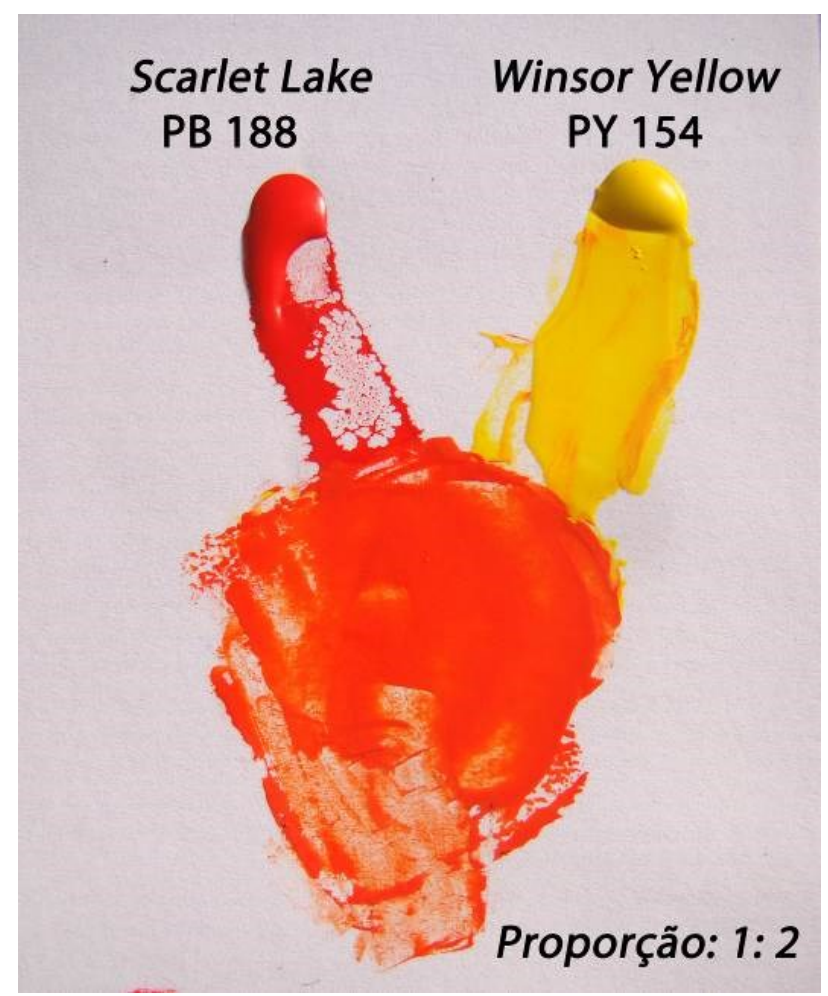

Figura 21: Mistura na paleta das aguarelas Scarlet Lake (PR 188) e Winsor Yellow (PY 154) na proporção 1:2. @Execução técnica e gráfica de Ana Bailão. 
A Mistura A resultou, inicialmente, da adição de partes iguais de Scarlet Lake (PR 188) e Winsor Yellow (PY 154). Todavia, o poder de tingimento de PR 188 é superior ao de PY 154, motivo pelo qual se adicionou mais uma parte de PY 154 para que o matiz obtido tivesse uma tendência tonal amarela (Fig. 21).

A semelhança da Mistura $A$, também na Mistura $B$ houve necessidade de adicionar mais quantidade de Winsor Lemon (PY 175) e menos de Winsor Blue (PB 15) devido ao elevado poder de tingimento deste último. Foram adicionadas 3 partes de PY 175 a uma de PB 15 (Fig.22).

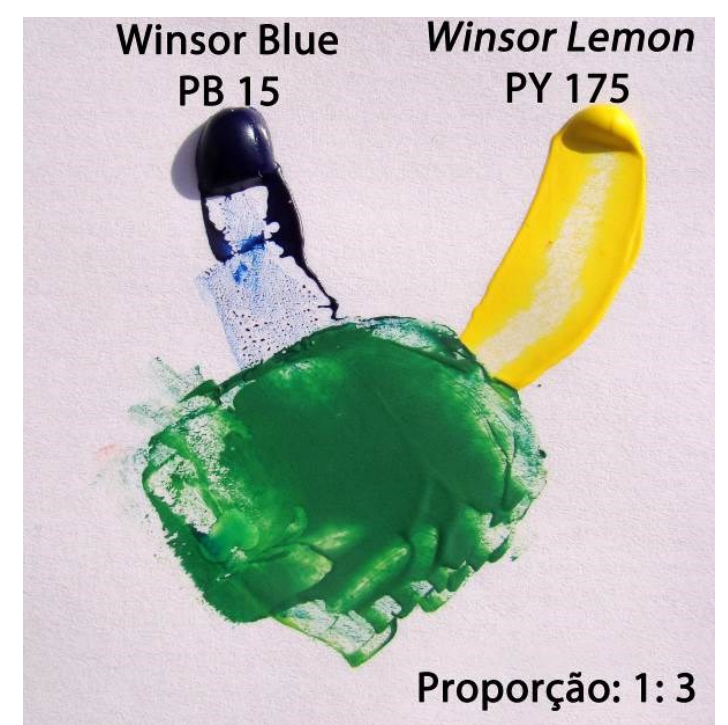

Figura 22: Mistura na paleta das aguarelas Winsor Blue (PB 15) e Winsor Lemon (PY 175) na proporção 1:3. ๑Execução técnica e gráfica de Ana Bailão.

O tom próximo da sombra queimada da W\&N foi obtido com a mescla dos resultados da Mistura $A$ + Mistura B, com maior proporção da Mistura A (2:1) (Fig. 23).

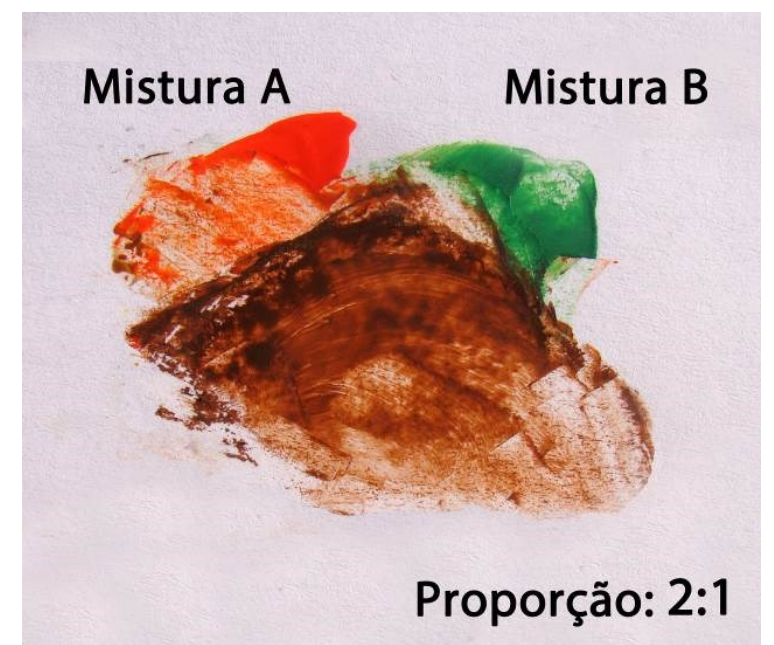

Figura 23: Mistura na paleta das aguarelas resultantes da Mistura A e B. @Execução técnica e gráfica de Ana Bailão. 
Como se pode observar na figura 24 há uma ligeira diferença entre o tom original da aguarela da W\&N e o reproduzido: o primeiro parece um pouco mais amarelo, mais saturado e mais luminoso do que o segundo.

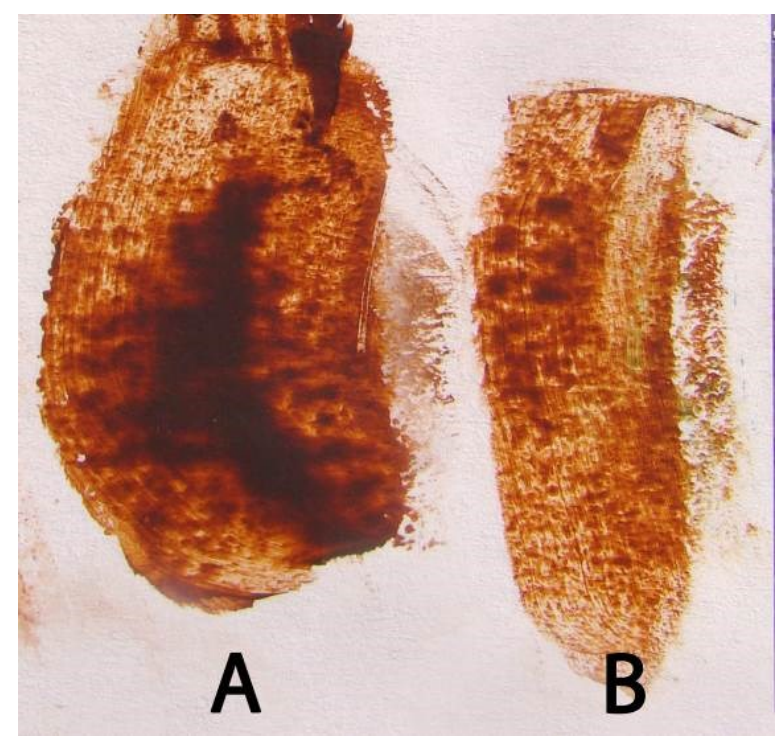

Figura 24: Comparação entre a aguarela Burnt Umber ( $\mathrm{PBr} 7$ ) (imagem $A$ ) e o resultado da Mistura $A+$ Mistura $B$ (imagem $B$ ). Embora a diferença seja ligeira, o matiz da esquerda é um pouco mais saturado e luminoso do que o da direita. @Execução técnica e gráfica de Ana Bailão.

Embora se pudesse aferir o tom final resultante das Misturas A + B com a adição de amarelo PY 154, o matiz obtido teria sempre uma luminosidade inferior ao pigmento $\mathrm{PBr} 7$ puro. Isto significa que, na prática, o matiz resultante da mistura das duas tintas pode parecer um pouco menos saturado e luminoso quando empregue sobre uma camada de tinta que não seja também ela pura. Importa referir que este fenómeno ocorrerá na reprodução de outros matizes.

Na pintura portuguesa, sobretudo na do século XVI, a sombra queimada é muito usada como camada final para a reintegração de lacunas localizadas no chão e nas montanhas. É essencial que tenha o máximo de luminosidade e saturação para que a reintegração realizada se aproxime da camada original. Além disso, as terras naturais e puras são essenciais devido ao seu baixo poder de tingimento. Sugere-se por isso a adição da sombra queimada $(\mathrm{PBr} 7)$ pura à paleta das seis cores já mencionadas ao longo do texto: Winsor Lemon (PY 175), Winsor Yellow (PY 154), Scarlet Lake (PR 188), Permanent Rose (PV 19), Winsor Blue (PB 15) e French Ultramarine (PB 29).

Para além do $\mathrm{PBr} 7$, tons como o negro e o branco, são importantes, sobretudo para uma reintegração mimética. A introdução do negro deve-se ao facto de não se conseguir obter um negro puro através da mistura de três tons, independentemente da tendência tonal dos matizes, e porque é necessário para ajuste na luminosidade e saturação. Quanto ao branco, também é útil para situações de ajustes da luz e de saturação, e para aumentar a opacidade de certos tons. Em relação ao negro, sugere-se o negro de marfim (PBk 9), por ter um tom castanho e um baixo poder de tingimento, e ser mais adequado, por exemplo, para matizar ligeiramente cores de vegetações e panejamentos. Em alternativa, sugere-se também o negro de marte (PBk 11) por ser mais opaco, podendo ser útil para reproduzir áreas onde o negro seja a cor dominante. Para o branco recomenda-se o branco de titânio (PW6) porque permite obter opacidade e poder de cobertura. 


\section{Conclusão}

O sistema dos dois amarelos, dois vermelhos e dois azuis aqui apresentado poderá ser uma alternativa para o conservador-restaurador que utiliza o sistema das três cores primárias ou para um iniciante na realização da reintegração cromática.

O estudo de caso exposto tenta exemplificar o modo como se podem manipular as cores atendendo às sua tendências tonais e recorrendo a um círculo cromático constituído a partir de medições colorimétricas de um conjunto de aguarelas. Este método pode ajudar o conservadorrestaurador a conhecer a priori as cores-pigmento mais indicadas para a reintegração cromática de uma determinada lacuna.

Este processo parece complexo quando os atributos da cor e todo o léxico inerente à teoria da cor não estão interiorizados. As tendências tonais das cores-pigmento são indicadas neste estudo como uma pista importante para reduzir o ensaio e as inúmeras tentativas durante a reprodução de um dado matiz. Esta metodologia pode ser aplicada com aguarelas, com guaches, com pigmento e verniz, entre outros. Para que isso aconteça é necessário que o conservadorrestaurador conheça bem as características individuais das cores-pigmento que utiliza.

A paleta das 9 cores-pigmento aqui sugerida implica a mistura de vários pigmentos para a obtenção de determinado tom, o que a longo prazo pode influenciar a estabilidade das corespigmento, bem como resultar na perda de saturação de cor. Assim, como contributo ao assunto exposto nesta pesquisa, propôs-se a inclusão de alguns pigmentos com o objetivo de serem utilizados puros sempre que possível. São eles: a sombra queimada $(\mathrm{PBr} 7)$, o negro de marfim (PBk 9) ou o negro de marte (PBk 11) e o branco de titânio (PW 6). À exceção do negro de marfim que é semi-transparente, os outros são opacos.

A utilização de uma paleta muito restrita dificulta a reprodução de tons de uma dada pintura, uma vez que existem matizes não reproduzíveis através de determinada gama de cores-pigmento. Convém ter pelo menos dois tons amarelos, dois vermelhos, dois azuis, de forte saturação e luminosidade, o branco e o preto, como cores neutras, e cores de valores mais suaves como as terras, muito úteis na reintegração cromática de pintura antiga.

\section{Agradecimentos}

Este estudo teve o apoio da Fundação para a Ciência e a Tecnologia (FCT) e QREN - POPH, cofinanciado pelo Governo Português e União Europeia através do MCTES. Esta investigação foi financiada pela bolsa se estudo da FCT SFRH/BD/69783/2010. Agradeço as indicações das minhas orientadoras Ana Calvo e Rocío Bruquetas, a ajuda terminológica de Arlindo Silva, as considerações técnicas de Frederico Henriques e as revisões de Lino Bailão.

\section{Notas}

[1] Em física, o comprimento de onda é a distância entre valores repetidos num padrão de onda. É usualmente representado pela letra grega lambda $(\lambda)$. Numa onda senoidal, o comprimento de onda é a distância entre picos (ou máximos) (González Cuasante et al. 2005: 26; Tornquist 2008: 29, 30).

[2] Os corpos físicos podem dividir-se em luminosos e não luminosos. Os corpos luminosos são aqueles que emitem a sua própria luz que os faz visíveis, enquanto os corpos não luminosos só são visíveis 
reflectindo ou devolvendo a luz que recebem de uma fonte luminosa. Este trabalho refere-se a estes últimos.

[3] A lista pode ser consultada no site do fabricante: http://www.winsornewton.com/products/watercolours/artists-water-colour/spectrum-lists/ ou no catálogo disponível em http://www.winsornewton.com/ assets/Leaflets/awcenglish.pdf. As temperaturas de cor dos pigmentos estão também disponibilizadas pela Gamblin Colors aqui: http://www.gamblincolors.com/navigating.color.space/color.temperature.color.html.

[4] $O$ índice de refracção $(\eta)$ é uma relação entre a velocidade da luz num determinado meio e a velocidade da luz no vácuo (c), equivalente a 1 . Em meios com índices de refracção mais baixos (próximos a 1) a velocidade da luz é maior (Gómez 2000: 191; Matteini e Moles 2001: 50; Gettens e Stout 1966: 147, 148a, 148b, 148c, 148d)

\section{Referências}

ALBERS, J. (2007). La interacción del color. Madrid: Alianza Editorial.

BALL, P. (2001). Bright Earth, Art and the invention of color. Chicago: University of Chicago Press.

DE LA ROJA DE LA ROJA, J. M. (2001). "Una nueva metodología en la ejecución del proceso de reintegración cromática". Pátina, n. 10 e 11: 96-101.

EDWARDS, B. (2006). El color. Un método para dominar el arte de combinar los colores. Barcelona: Ediciones Urano.

BRIGGS, D. (2012). The Dimension of colour. http://www.huevaluechroma.com/061.php. [Consulta: 15. 05. $\left.201^{3}\right]$.

CIE (1987). International Lighting Vocabulary. Vienna: CIE Publ. No. 17.4.

FAIRCHILD, M. D. (2005). Color Appearance Models. Second Edition. Chichester, UK: John Wiley \& Sons, Ltd.

FOUTAIN STUDIO. Learning to Mix Colors. http://fountainstudio.com/ watercolor\%20tips/tipmixing_colors.html. [Consulta: 17. 05. 2013].

GETTENS, R. J.; STOUT, G. L. (1966). Painting Materials. A short encyclopedia. New York: Dover Publications GONZÁLEZ, J. M.; CUEVAS, M. del M.; FERNÁNDEZ, B. (2005). Introducción al color. Madrid: Akal Bellas Artes. GOTTSEGEN, M. D. (2006). The Painter Handbook. Nova lorque: Watson-Guptill Publications.

GÓMEZ, M. L. (2000). La Restauración. Examen científico aplicado a la conservación de obras de arte. 2.a ed. Madrid: Catedra Cuadernos Arte/Instituto Del Patrimonio Histórico Español.

HECHT, E. (2002) - Óptica. 2. a ed. Lisboa: Fundação Calouste Gulbenkian.

HICKETHIER, A. (1969). Le Cube des Coulers. Paris: Dessain et Tolra.

KUPPERS, H. (1975). La couleur. Origine, methodologie, application. Fibourg: Office du Livre.

LOUÇÃO, M. D. (1992). Cor: natureza, ordem, percepção. Dissertação para Doutoramento em Arquitectura pela Faculdade de Arquitectura da Universidade Técnica de Lisboa.

MARTEL, C. (1855). Principles of colouring in Painting. Londres: Winsor and Newton.

MAYER, R. (2006). Manual do Artista de Técnicas e Materiais. São Paulo: Livraria Martins Fontes Editora.

MATTEINI, M.; MOLES, A. (2001). Ciencia y restauración. Andalucía: Nerea.

PYLE, D.; PEARCE, E. (2009). The Oil Colour Book. A comprehensive resource for painters. Harrow, Inglaterra:

ColArt Fine Art \& Graphics Ltd, p. 17. http://www.winsornewton.com. [Consulta: 19. 05. 2013]. 
SAUNDERS, D. (2000). Retouching: colour vision and optical considerations. In Conference 2000; Retouching Filling. Oxford: Association of British Picture Restorers, pp. 3-9.

SCHMINCKE. (2010). HORADAM AQUARELL Finest artists' water-colours - Series 14. http://www.tempera.fi/Horadam.pdf. [Consulta: 19. 11. 2013].

TORNQUIST, J. (2008). Color y Luz. Teoría y práctica. Barcelona: Editorial Gustavo Gili.

TRUAN LAKA, M. (2013). Introducción a la Pintura a través del color. País Vasco: Universidad del País Vasco.

URLAND, A. (1999). Colour Specification and measurement. Conservation of Architectural Heritage, Historic Structures and Materials. ARC Laboratory Handbook. Rome: ICCROM UNESCO WHC, Vol.5.

WINSOR \& NEWTON. (2005). Artists' Water Colour. Perfecting the Fine Art of Water Colours. http://www.winsornewton.com/assets/Leaflets/awcenglish.pdf. [Consulta: 19. 11. 2013].

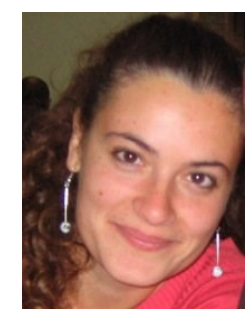

\section{Ana Bailão}

Universidade Católica Portuguesa (UCP)

ana.bailao@gmail.com

Ana Bailão é licenciada (pré-bolonha) em Conservação e Restauro pelo Instituto Politécnico de Tomar (2005) e mestre pela Universidade Católica Portuguesa (2010). O tema de investigação foi sobre as metodologías e as técnicas de reintegração cromática em pintura de cavalete. Atualmente, é doutoranda na mesma instituição, em colaboração com o Centro de Investigação em Ciência e Tecnologia das Artes (CITAR) e o Instituto del Patrimonio Cultural de España (IPCE). O seu tema de doutoramente é sobre os criterios de intervenção e estratégias para a avaliação da qualidade em reintegração cromática de pintura de cavalete.

Artículo enviado el 17/06/2013

Artículo aceptado el 23/11/2013 